FRANK MOSHÉ COTACALLAPA CHOQUE

Modelos de propagação de epidemias em redes complexas

São Paulo

2015 
FRANK MOSHÉ COTACALLAPA CHOQUE

\section{Modelos de propagação de epidemias em redes complexas}

Dissertação apresentada à Escola de Artes, Ciências e Humanidades da Universidade de São Paulo como parte dos requisitos para a obtenção do título de Mestre em Ciências pelo Programa de Pós-Graduação em Modelagem de Sistemas Complexos.

Versão corrigida contendo as alterações solicitadas pela comissão julgadora em 05 de março de 2015. A versão original encontra-se em acervo reservado na Biblioteca da EACHUSP de acordo com a resolução CoPGr 6018 de outubro de 2011.

Orientador: Masayuki O. Hase

São Paulo 
Autorizo a reprodução e divulgação total ou parcial deste trabalho, por qualquer meio convencional ou eletrônico, para fins de estudo e pesquisa, desde que citada a fonte.

CATALOGAÇÃO-NA-PUBLICAÇÃO

(Universidade de São Paulo. Escola de Artes, Ciências e Humanidades. Biblioteca)

Cotacallapa Choque, Frank Moshe

Modelos de propagação de epidemias em redes complexas / Frank

Moshe Cotacallapa Choque ; orientador, Masayuki Oka Hase. - São

Paulo, 2015

$86 \mathrm{f}$.

Dissertação (Mestrado em Ciências) - Programa de PósGraduação em Modelagem de Sistemas Complexos, Escola de Artes, Ciências e Humanidades, Universidade de São Paulo

Versão corrigida

1. Sistemas dinâmicos . 2. Epidemiologia - Modelos

matemáticos. 3. Redes complexas - Simulação computacional. I. Hase, Masayuki Oka, orient. II. Título

CDD 22.ed. - 530.131 
Nome: Frank Moshé Cotacallapa Choque

Título: Modelos de propagação de epidemias em redes complexas

Dissertação apresentada à Escola de Artes, Ciências e Humanidades da Universidade de São Paulo como parte dos requisitos para a obtenção do título de Mestre em Ciências pelo Programa de Pós-Graduação em Modelagem de Sistemas Complexos.

Versão corrigida contendo as alterações solicitadas pela comissão julgadora em 05 de março de 2015. A versão original encontra-se em acervo reservado na Biblioteca da EACHUSP de acordo com a resolução CoPGr 6018 de outubro de 2011.

Orientador: Masayuki O. Hase

Aprovado em: 05/03/2015

Banca Examinadora:

Prof. Dr. Marcos Gonçalves Quiles

Instituição: Universidade Federal de São Paulo (UNIFESP)

Prof. Dr. José Ricardo Gonçalves de Mendonça

Instituição: Universidade de São Paulo (USP)

Prof. Dr. Masayuki Oka Hase

Instituição: Universidade de São Paulo (USP)

\section{São Paulo}




\section{Agradecimentos}

À Deus.

Ao Prof. Masayuki Oka Hase, pela paciência, confiança, ensinamentos e impecável condução deste trabalho.

Aos colegas e professores do Programa de Pós-Graduação em Modelagem de Sistemas Complexos, pela amizade e os momentos inesquecíveis ao longo do mestrado.

À Organização dos Estados Americanos (OEA) e à Universidade de São Paulo (USP), pelo suporte financeiro e a formação acadêmica. 


\section{Resumo}

COTACALLAPA CHOQUE, Frank Moshé. Modelos de propagação de epidemias em redes complexas. 2015. 86 f. Dissertação (Mestrado em Ciências) - Escola de Artes, Ciências e Humanidades, Universidade de São Paulo, São Paulo, 2015.

A pesquisa na área de redes complexas tem evoluído bastante, e é nesta linha que o presente trabalho visa aportar, dando ênfase especial no processo epidêmico sobre redes. Desse modo, foi feito uma análise geral das redes complexas em conjunto com suas propriedades. Após isso, desenvolveu-se o processo de contágio da epidemia do tipo suscetível-infectado sobre uma rede aleatória uniforme e sobre uma rede aleatória com ligações preferenciais. Ambas abordagens foram desenvolvidas usando equações mestras para finalmente fazer sua análise com métodos analíticos e computacionais.

Palavras chave: Redes complexas. Equação mestra. Epidemia. 


\section{Abstract}

COTACALLAPA CHOQUE, Frank Moshé. Propagation models of epidemics in complex networks. 2015. 86 f. Dissertation (Master of Science) - Escola de Artes, Ciências e Humanidades, Universidade de São Paulo, São Paulo, 2015.

Research in the area of complex networks has evolved greatly, and over this line that this present work aims to contribute, with particular emphasis on the epidemic process over networks. Along these lines, a general review about complex networks is made with their main properties. After that, a susceptible-infected contagion process is developed over a uniform random network and a preferential attachment network. Both approaches were developed using master equations to finally analyze them with analytical and computational methods.

Keywords: Complex networks. Master equations. Epidemics. 


\section{Lista de figuras}

Figura 1 - Modelo da rede de Enron . . . . . . . . . . . . . . . . . 11

Figura 2 - Grafo das pontes de Königsberg . . . . . . . . . . . . . . . . 20

Figura 3 - Processo de construção da rede . . . . . . . . . . . . . . . . 23

Figura 4 - Processo de construção da rede Aleatória Uniforme . . . . . . . . . . 25

Figura 5 - Processo de construção da rede de Barabási-Albert . . . . . . . . . . . 27

Figura 6 - Modelos de rede: Barabási-Albert e Erdös-Rényi . . . . . . . . . . . . 28

Figura 7 - Comparação das distribuições de grau . . . . . . . . . . . . . . . . . 29

Figura 8 - Processo de contágio . . . . . . . . . . . . . 31

Figura 9 - Preferência geral e preferência epidêmica . . . . . . . . . . . . 33

Figura 10 - Lista comparativa de modelos . . . . . . . . . . . . . . . . . . . 33

Figura 11 - Epidemia recozida no modelo de Barabási-Albert . . . . . . . . . . . . 35

Figura 12 - Epidemia temperada no modelo de Barabási-Albert . . . . . . . . . . 35

Figura 13 - Distribuição da epidemia temperada na rede de Barabási-Albert mediante simulação . . . . . . . . . . . . . . . . . . 36

Figura 14 - Distribuição da epidemia temperada no modelo de Barabási-Albert resultado analítico . . . . . . . . . . . . . . . . 36

Figura 15 - Distribuição da epidemia temperada e recozida no modelo da rede de Barabási-Albert - resultado analítico . . . . . . . . . . . . . . . . 37

Figura 16 - Distribuição da epidemia recozida no modelo aleatório uniforme - resultado analítico . . . . . . . . . . . . . . . . . . . 38

Figura 17 - Distribuição da epidemia temperada no modelo aleatório uniforme resultado analítico . . . . . . . . . . . . . . . . 39

Figura 18 - Distribuição da epidemia temperada no modelo aleatório uniforme resultado da simulação . . . . . . . . . . . . . . . . . . . . . . . 40

Figura 19 - Distribuição da epidemia temperada no modelo aleatório uniforme resultado da simulação . . . . . . . . . . . . . . . . . . . . . . . . . . . 40

Figura 20 - Distribuição de propagação variável temperada sobre o modelo aleatório uniforme - resultado analítico . . . . . . . . . . . . . . 42

Figura 21 - Distribuição da epidemia temperada no modelo Barabási-Albert (modelo C) - resultado da simulação . . . . . . . . . . . . . . . .

Figura 22 - Distribuição da epidemia na rede de Barabási-Albert com preferência geral e contágio variável 


\section{Sumário}

INTRODUÇÃO $\ldots \ldots \ldots \ldots \ldots \ldots \ldots \ldots$

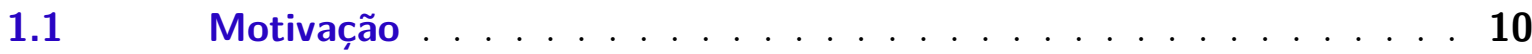

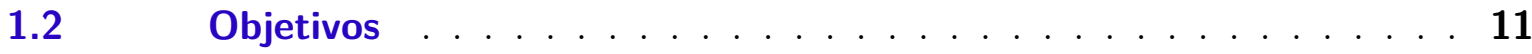

$1.3 \quad$ Organização do texto $\ldots \ldots \ldots \ldots \ldots \ldots \ldots \ldots \ldots$

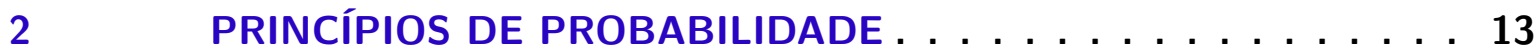

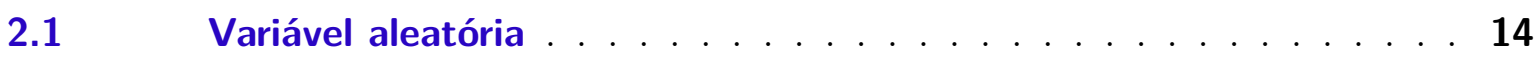

2.2 Distribuições de probabilidade discretas . . . . . . . . . . 16

2.2.1 Distribuição de Bernoulli . . . . . . . . . . . . . . . . . 16

2.2.2 Distribuição binomial . . . . . . . . . . . . . . . . . . . . 16

2.2 .3 Distribuição de Poisson . . . . . . . . . . . . . . . . . . . . . 17

2.3 Distribuição de probabilidade contínuas . . . . . . . . . 18

2.3 .1 Distribuição uniforme . . . . . . . . . . . . . . . . . . . . 18

3 MODELOS DE REDES $\ldots \ldots \ldots \ldots \ldots \ldots \ldots \ldots$

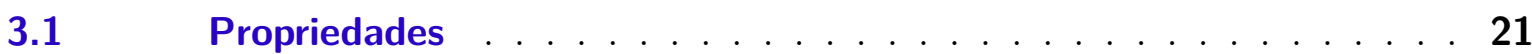

3.1 .1 Aglomeração . . . . . . . . . . . . . . . . . . . 22

3.1 .2 Distribuição de grau . . . . . . . . . . . . . . 22

3.1.3 Detecção de comunidades . . . . . . . . . . . . . . . . . 22

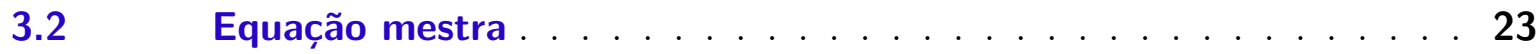

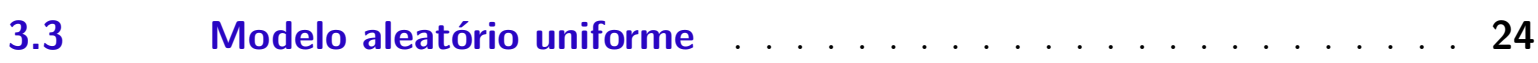

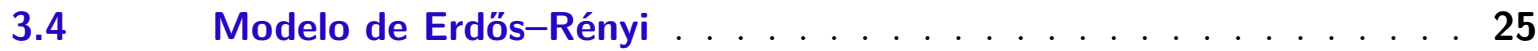

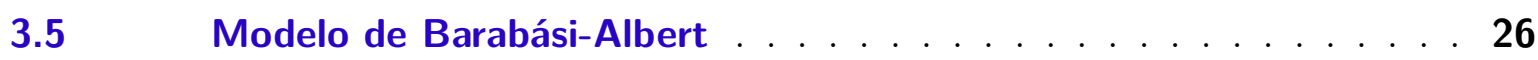

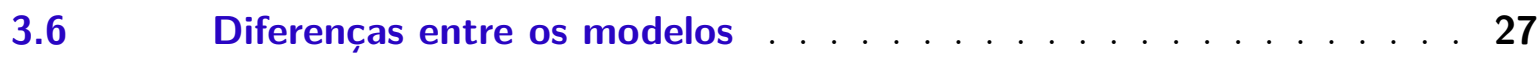

$3.7 \quad$ Epidemia . . . . . . . . . . . . . . . . . . 28

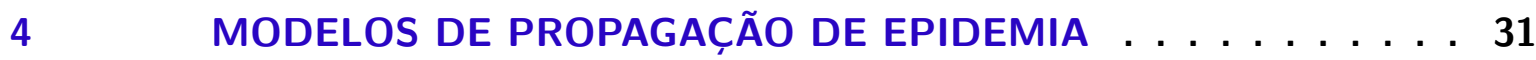

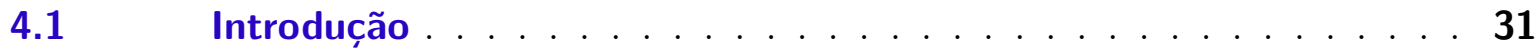

$4.2 \quad$ Modelo $\mathrm{A}$ ou contágio fixo $\ldots \ldots \ldots \ldots \ldots \ldots$

4.2.1 Epidemia recozida sobre a rede Barabási-Albert . . . . . . . . . . . . 34

4.2.2 Epidemia temperada sobre a rede de Barabási-Albert . . . . . . . . . . 34

4.2 .3 Discussão . . . . . . . . . . . . . . . . . . 35

4.2.4 Epidemia recozida sobre a rede aleatória uniforme . . . . . . . . . . 37

4.2.5 Epidemia temperada sobre a rede aleatória uniforme . . . . . . . 38

4.2 .6 Discussão . . . . . . . . . . . . . . . . . . . 38

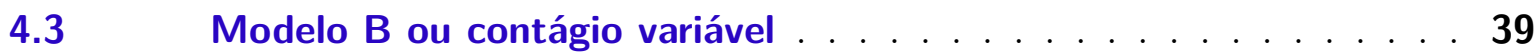


4.3.1 Contágio variável sobre a rede aleatória uniforme . . . . . . . . . . . . 40

4.3.2 Contágio variável sobre a rede de Barabási-Albert . . . . . . . . . . . . . . 41

4.3.3 Discussão . . . . . . . . . . . . . . . . . . . . . . . . . . . 41

4.4 Modelo C ou preferência epidêmica . . . . . . . . . . . . 42

$4.4 .1 \quad$ Discussão . . . . . . . . . . . . . . . . . . . . . 43

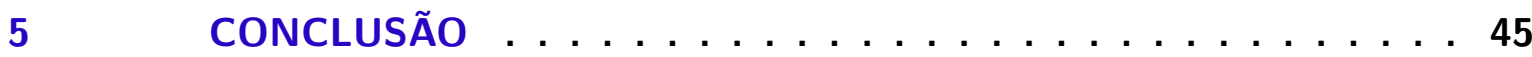

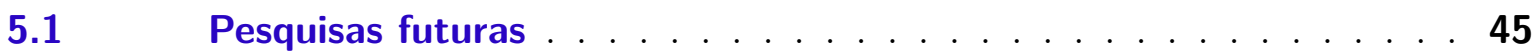

Referências . . . . . . . . . . . . . . . . 47

$\begin{array}{ll}\text { APÊNDICES } & 51\end{array}$

APÊNDICE A - EQUAÇÃO MESTRA PARA REDE ALEATÓRIA SIMPLES . . . . . . . . . . . . 53

APÊNDICE B - MODELO DE ERDŐS-RÉNYI . . . . . . . . 56

APÊNDICE C - MODELO DE BARABÁSI-ALBERT . . . . . . . 59

APÊNDICE D - CÓDIGO DE GERAÇÃO DE REDES EM PYTHON 63

APÊNDICE E - TRANSFORMADA Z - MODELO DE BARABÁSI-

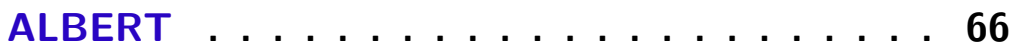

APÊNDICE F - PROPAGAÇÃO DE EPIDEMIA . . . . . . . . 70

APÊNDICE G - CONTÁGIO VARIÁVEL . . . . . . . . . . . . . 74 


\section{Introdução}

\subsection{Motivação}

Segundo Barabási (2013), os sistemas complexos são formados por diversas partes que interagem entre elas, e essas partes e suas interações podem ser representadas por meio de redes complexas. Esta capacidade de abstração em redes tem ajudado no aprofundamento de sistemas complexos. Nesse sentido, desde o começo do século XXI, temos presenciado o avanço rápido do estudo das redes complexas em diversas áreas. Um exemplo é a compilação elaborada por Newman (2003, p. 182) sobre as redes encontradas na biologia, tecnologia e ciências sociais.

Aliás, um dos fenômenos que é possível encontrar em alguns dos sistemas complexos é a propagação de elementos, que podem ser doenças, boatos, notícias, publicidade, entre outros. A propagação de doenças sobre certas condições pode dar origem a uma epidemia e procura-se minimizar o efeito dela. Em outros casos como a publicidade, procura-se maximizar a propagação dela. Considerando isso, diversos pesquisadores optaram pelo uso das redes complexas no intuito de entender este fenômeno; desse modo, foram desenvolvidos diversos modelos matemáticos e simulações seguindo diferentes processos de contágio e sobre variadas estruturas de redes, como mostram Bocaletti et al. (2006, p. 228) e Newman, Barabási e Watts (2006, p. 415).

A análise de uma situação real onde é possível aplicar as redes é o seguinte exemplo. No ano de 1985 foi fundado a Enron, uma empresa de energia que teve muito sucesso e durante os 15 anos da sua existência virou a sétima maior companhia dos Estados Unidos da América. Devido à desregulamentação no setor de energia e a sua rápida adaptação no mercado intermediário de energia entre consumidores e fornecedores, a empresa cresceu rapidamente, o que lhe permitiu usar os conhecimentos que possuía para aplicá-las em outros setores, como afirma Curral e Epstein (2003); assim, no ano 2001, a Enron tinha 21 mil empregados ao redor de 40 países segundo Ali (2011).

A pesquisa feita por Chapanond, Krishnamoorthy e Yener (2005) mostra que uma série de decisões irregulares, pouca informação transparente e o aparente sucesso na bolsa de valores levaram a Enron à falência no ano 2001. Embora isso fosse um acontecimento supreendente para muitas pessoas, os principais diretores, empresas de avaliação de riscos, bancos e outras organizações sabiam de fato que isto poderia acontecer. De modo claro, uma das causas da crise foi a não abertura da informação do estado real da empresa, e a prova disso são os resultados de pesquisadores como Diesner, Frantz e Carley (2005) da Carnegie Mellon University, que fizeram uma análise dos emails da empresa usando o Processamento de Linguagem Natural (NLP) e técnicas de análise de redes, e finalmente 
obtiveram a estrutura da rede interna da empresa baseada apenas na troca de emails. Os resultados do estudo mostraram que de fato em outubro de 2000, antes de começar a crise, as comunicações eram hierárquicas. Isso explica que existiam canais formais para o envio de informação. Já em outubro de 2001 a rede mudou, e mostra que as interações eram mais informais, criando canais de comunicação que não seguiam a ordem hierárquica entre os funcionários da empresa. Ao mesmo tempo, o compartilhamento da informação não manteve o mesmo ritmo e algumas posições-chaves tiveram uma redução na quantidade de emails que eram antes enviadas normalmente, passando a ser de emissores ativos de informação para simples receptores. Isso fez com que a informação ficasse detida em algumas posições importantes da rede e sem compartilhamento (ver Figura 1).

Figura 1 - Comparação da rede de envio de emails entre empregados e diretores da Enron entre outubro de 2000 e outubro de 2001

(a) Outubro de 2000

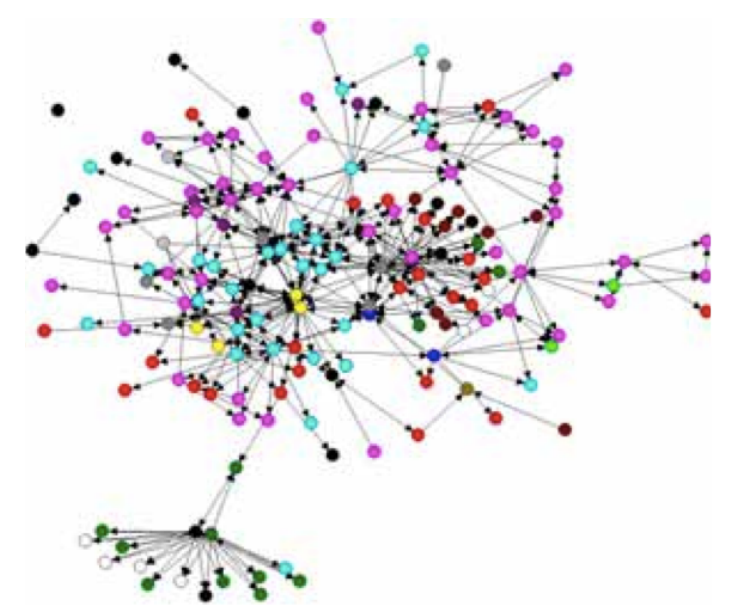

(b) Outubro de 2001

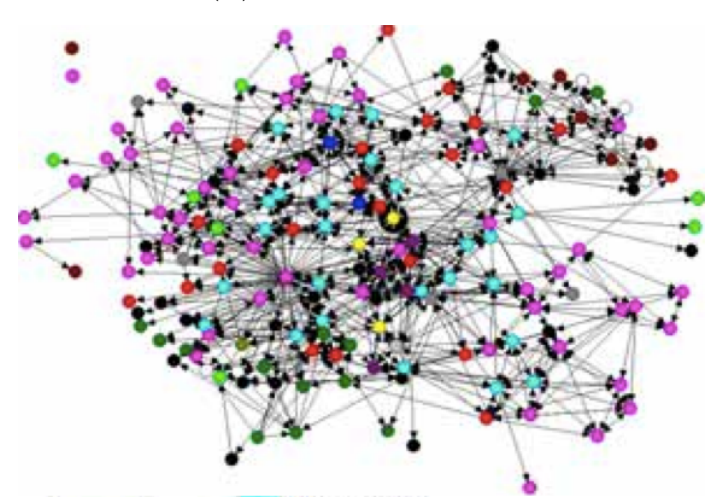

Fonte: Chapanond, Krishnamoorthy e Yener (2005).

Se analisarmos superficialmente o caso da Enron fazendo um estudo da rede dos emails, observamos que é basicamente um problema de propagação de informação confiável entre os empregados da empresa.

Finalmente, as redes complexas em si é um tema de muito interesse, e o foco neste texto tem como finalidade analisar o fenômeno da propagação sobre estas de uma perspectiva analítica e computacional.

\subsection{Objetivos}

O principal objetivo da pesquisa é apresentar os modelos de epidemia suscetívelinfectado (SI) seguindo a abordagem de equações mestras através de uma perspectiva analítica e computacional. Desse modo, propõe-se modelos de epidemia teóricos sobre dois tipos de redes. A primeira é sobre uma rede aleatória uniforme e a segunda sobre uma rede aleatória com preferência de ligação (modelo de Barabási-Albert). Além disso, procura-se 
desenvolver simulações computacionais da propagação seguindo o mesmo processo dos modelos teóricos e desse modo analisar e comparar resultados.

\subsection{Organização do texto}

Ao longo do texto é apresentado o desenvolvimento de vários modelos de propagação sobre redes complexas com seus respectivos resultados analíticos e simulações computacionais.

No capítulo dois é feita uma introdução básica sobre probabilidades e suas propriedades principais. Posteriormente, no capítulo três são abordados os principais modelos de redes complexas e uma análise das suas principais propriedades. Em seguida, são apresentados os modelos de propagação sobre redes complexas no capítulo quatro, para finalmente terminar com as conclusões no capítulo cinco. 


\section{Princípios de probabilidade}

Este capítulo desenvolve o conteúdo fundamental sobre teoria de probabilidades. Os conceitos serão usados nos capítulos seguintes para análise e formulação dos modelos de redes complexas. O conteúdo será apresentado de forma sucinta neste capítulo e é baseado nos livros sobre probabilidades de Ash (2008), Cameron (2000) e Grinstead e Snell (1997).

Como afirma Cameron (2000), não existe uma definição exata de probabilidade; porém, a partir de uma perspectiva matemática é possível definir alguns axiomas básicos para depois construir algumas propriedades e definições sobre probabilidades. Quando observamos um evento que acontece na natureza ou em simulações, é usado o termo experimento para definir esse processo de observação ou contagem, sendo que ele pode trazer ou não resultados numéricos. Alguns exemplos de experimentos são: entrevista com uma pessoa, medir a quantidade de chuva, entre outros. Assim, para um determinado experimento podem existir diferentes resultados, e o conjunto dos resultados possíveis é conhecido como espaço amostral e denotado por $\Omega$, e qualquer subconjunto do espaço amostral é nomeado como evento.

Para ter um melhor entendimento das definições, suponhamos que o experimento seja o lançamento de duas moedas; o seu espaço amostral é

$$
\Omega=\{\text { cara-cara, cara-coroa, coroa-cara, coroa-coroa }\}
$$

e seja $A$ um evento particular desse experimento que representa o conjunto dos resultados na qual 'as duas moedas mostram a mesma face'; então,

$$
A=\{\text { cara-cara, coroa-coroa }\}
$$

Um evento é simples quando é formado por apenas um resultado possível, e é nomeado como composto quando é formado por mais de um resultado possível. Usando o exemplo anterior, podemos afirmar que o evento $A$ é um evento composto.

Sejam $B$ e $C$ dois eventos; então, é possível definir $B \cup C$ como representação da união dos resultados em $B$ ou $C$ (ou ambos), e $B \cap C$ consiste no conjunto de resultados que estão em $B$ e $C$. Sejam $A_{1}, A_{2}, A_{3}, \ldots$ eventos de um experimento; eles são eventos mutuamente exclusivos quando para qualquer $i \neq j$ temos $A_{i} \cap A_{j}=\varnothing$. Baseado nas definições apresentadas, é possível definir a probabilidade matematicamente segundo os três axiomas desenvolvidos pelo matemático russo A. N. Kolmogorov.

Supondo que $A$ seja um evento, e sendo $\Omega$ o seu espaço amostral, então a probabi- 
lidade de $A$ é

$$
P(A)=\frac{\text { quantidade de resultados possíveis de } A}{\text { quantidade total de resultados de } \Omega} .
$$

- Para qualquer evento $A, P(A) \geq 0$.

- $P(\Omega)=1$.

- Se $A_{1}, A_{2}, A_{3}, \ldots$ são eventos mutuamente exclusivos, então

$$
P\left(\bigcup_{i=1}^{\infty} A_{i}\right)=\sum_{i=1}^{\infty} P\left(A_{i}\right)
$$

quando temos uma quantidade enumerável infinita de eventos.

Outro conceito importante é a independência de eventos. Dizemos que dois eventos $A$ e $B$ são independentes quando a probabilidade do evento $B$ não é influenciado ou mudado quando acontece o evento $A$, e vice-versa. (ROLLA, 2013). Neste caso, $P(A \cap B)=$ $P(A) P(B)$. Quando o evento $A$ acontece dado o evento $B$, esta probabilidade condicional é denotada por $P(A \mid B)$. Ademais, temos

$$
P(A \cap B)=P(A) P(B \mid A) \text { ou } P(A \cap B)=P(B) P(A \mid B)
$$

assim, a probabilidade condicionada do evento $A$ dado $B$ é definida como

$$
P(A \mid B)=\frac{P(A \cap B)}{P(B)} \text { se } P(B) \neq 0,
$$

e quando $A$ e $B$ são independentes, então $P(A \mid B)=P(A)$.

Dois eventos são independentes se, e somente se, $P(A \cap B)=P(A) P(B)$. De outro modo, os dois eventos são dependentes.

\subsection{Variável aleatória}

Uma variável aleatória $X$ é uma função definida em um espaço amostral, e é denotada como

$$
X: \Omega \rightarrow \mathbb{R}
$$

Como exemplo, se uma moeda é lançada 5 vezes, então o espaço amostral desse experimento contém $2^{5}$ elementos. Também é possível afirmar que $X$ é uma variável aleatória que representa o número de coroas presentes no lançamento. Desse modo, supondo que $c=$ cara 
e $k=$ coroa, escolhemos um elemento particular de $\Omega$, e suponha que seja $(c-c-k-k-c)$; então, $X(c-c-k-k-c)=2$. Outro exemplo é se escolhemos aleatoriamente uma pessoa de um grupo determinado de pessoas, e medimos o tamanho dela ou dele. Neste caso particular, o espaço amostral é o grupo de pessoas, e a variável aleatória é o tamanho.

Se analisarmos o primeiro exemplo, a variável aleatória possui uma separação de uma unidade entre cada possível valor. Neste caso, a quantidade de coroas vai de 0 até 5, com separação de uma unidade entre cada possível valor. Já no segundo exemplo, o tamanho de cada pessoa não possui uma quantidade fixa de possíveis valores.

Considerando o primeiro exemplo, definimos que uma variável aleatória é discreta quando os seus valores são finitos ou infinitos enumeráveis. Uma variável aleatória é contínua quando os seus valores são infinitos e não-enumeráveis, e usualmente eles são separados em intervalos.

Uma função de probabilidade $\mathrm{P}$ de uma variável aleatória é uma função que possui domínio no subconjunto de espaço amostral e cumpre duas condições no caso discreto:

- $0 \leq P(X=x)$

- $\sum_{x \in \Omega} P(X=x)=1$

Aqui, $x$ representa os valores da variável aleatória $X, P(X=x)$ representa a probabilidade de $x$ e $\Omega$ o espaço amostral. Como exemplo, suponhamos que lancemos uma moeda três vezes, e repetimos este experimento oito vezes. Seja $X$ a variável aleatória que define o número total de coroas $(k)$ e o espaço amostral que resulta do experimento é $\Omega=\{c k c, k k k, c k k, k c k, c c c, k k k, c c k, c k c\}$, onde $c$ representa a cara da moeda. Desse modo, os valores da variável aleatória são $X=\{0,1,2,3\}$ e sua correspondente distribuição de probabilidade é formada por $P(X) \in\left\{\frac{1}{8}, \frac{3}{8}, \frac{2}{8}, \frac{2}{8}\right\}$.

Baseado na distribuição de probabilidade, outra definição importante é o valor esperado de $X$, que é denotada por $E(X)$ ou $\mu$ :

$$
\mu=E(X)=\sum_{i} x_{i} P\left(X=x_{i}\right)
$$

onde a soma é realizada sobre todos os valores da variável aleatória $X$ multiplicado pela sua correspondente probabilidade. Este resultado é o valor que se espera observar em média se o experimento é repetido várias vezes.

Segundo Mendenhall, Beaver e Beaver (2013) e Rolla (2013), outras medidas importantes são a variância $\left(\sigma^{2}\right)$ e o desvio padrão $(\sigma)$, onde a primeira representa a 
medida de dispersão que mostra o quão distantes os valores estão da média e o desvio padrão é a raiz quadrada da variância. Assim, a variância é definida por

$$
\sigma^{2}=E\left[(X-\mu)^{2}\right]=\sum_{i}\left(x_{i}-\mu\right)^{2} P\left(X=x_{i}\right)
$$

\subsection{Distribuições de probabilidade discretas}

Existem diferentes tipos e exemplos de variáveis aleatórias discretas. No entanto, ao longo deste texto serão apresentadas as três mais importantes para esta dissertação: distribuição de Bernoulli, binomial e a de Poisson.

\subsubsection{Distribuição de Bernoulli}

A distribuição de Bernoulli considera duas variáveis, 0 e 1, sendo considerado como sucesso quando é 1 , e fracasso quando é 0 . Seja $p$ a probabilidade para $X=1$; então, para $X=0$, a probabilidade é $1-p$.

O valor esperado e variância para esta distribuição são

$$
\begin{aligned}
\mu & =0 \cdot q+1 \cdot p=p \\
\sigma^{2} & =\operatorname{Var}(X)=0^{2} \cdot q+1^{2} \cdot p-p^{2}=p q, \\
\sigma & =D p(X)=\sqrt{p q}
\end{aligned}
$$

lembrando que $q=1-p$.

\subsubsection{Distribuição binomial}

A distribuição binomial é resultado da contagem de sucessos em $n$ experimentos independentes associados à distribuição de Bernoulli, isto é,

- O experimento é repetido $n$ vezes de modo idêntico.

- Cada repetição tem dois resultados possíveis; o primeiro é chamado de sucesso e o segundo de fracasso.

- A probabilidade do sucesso em uma experiência é igual a $p$, e ela continua com o mesmo valor fixo em todas as repetições. Então, a probabilidade de fracasso é $(1-p)=q$.

- Cada repetição é independente. 
- O objetivo é saber o número de sucessos ao longo das $n$ repetições, $X=0,1,2,3, \ldots n$, onde $X$ é o número de sucessos.

Assim, a distribuição da probabilidade de ter $k$ sucessos em $n$ repetições é

$$
P[X=k]=\left(\begin{array}{l}
n \\
k
\end{array}\right) p^{k} q^{n-k}
$$

e isto é assim devido à possibilidade de ter $\left(\begin{array}{l}n \\ k\end{array}\right)$ formas de obter $k$ sucessos ao longo de $n$ repetições. Esta distribuição possui as seguintes medidas:

$$
\begin{aligned}
\mu & =n p \\
\sigma^{2} & =\operatorname{Var}(X)=n p q \quad \mathrm{e} \\
\sigma & =D p(X)=\sqrt{n p q} .
\end{aligned}
$$

\subsubsection{Distribuição de Poisson}

Outra distribuição importante é a descoberta por Simeón-Denis Poisson, que usualmente é observada com a ocorrência de muitos eventos aleatórios durante um determinado espaço de tempo ou período. Esta distribuição é resultado de um número grande de repetições, na qual existe uma probabilidade pequena de sucessos, seguindo um processo similar da distribuição binomial. No entanto, é dificil obter a distribuição de probabilidade com essas condições.

Assim, seja $\lambda$ a quantidade de vezes que um evento ocorre em um determinado período de tempo em $n$ realizações; então, a probabilidade de ter $k$ ocorrências deste evento é

$$
P(X=k)=e^{-\lambda} \frac{\lambda^{k}}{k !}
$$

onde $\lambda$ é um valor constante e tem as seguintes propriedades:

$$
\begin{aligned}
\mu & =\lambda=n p, \\
\sigma^{2} & =\lambda \quad \mathrm{e} \\
\sigma & =\sqrt{\lambda} .
\end{aligned}
$$




\subsection{Distribuição de probabilidade contínuas}

Até agora foram apresentadas as distribuições de probabilidade de variáveis discretas. No entanto, existem variáveis tais como peso, tamanho, que podem ter valores contínuos e precisam de outra abordagem.

Considerando isso, chamamos de densidade à função não negativa que representa a distribuição de probabilidade para variáveis contínuas; ela é representada como $f(x)$, chamada de função densidade de probabilidade da variável aleatória $x$. Além disso, cumpre duas propriedades:

- $\int_{-\infty}^{+\infty} f(x) \mathrm{d} x=1$.

- A probabilidade que uma variável $X$ possa se encontrar em um intervalo particular (entre $a$ e $b$ ) é igual à area nesse intervalo, isto é, $P([a, b])=\int_{a}^{b} f(x) \mathrm{d} x$.

É necessário ter em consideração algumas diferenças entre os dois tipos de variáveis (discreta e contínua). Seja $X$ uma variável contínua e $a$ um valor particular de $x$; então,

- $P(X=a)=0$.

- O anterior implica $P(X \geq a)=P(X>a)$ e $P(X \leq a)=P(X<a)$.

Da mesma forma que existem distribuições de probabilidade importantes para variáveis discretas, também existem para as contínuas.

\subsubsection{Distribuição uniforme}

Esta distribuição é a mais simples das variáveis contínuas, e consiste em gerar probabilidades proporcionais ao tamanho do intervalo.

Assim, quando a variável aleatória $X$ tem valores entre $a$ e $b$, e $a<b$, a distribuição é

$$
f(x)=\left\{\begin{array}{cc}
\frac{1}{b-a}, & a \leq x \leq b \\
0, & x<a ; b<x
\end{array}\right.
$$

com as seguintes propriedades: 


$$
\begin{aligned}
\mu & =\frac{a+b}{2} . \\
\sigma^{2} & =\frac{(b-a)^{2}}{12} \mathrm{e} \\
\sigma & =\frac{b-a}{\sqrt{12}} .
\end{aligned}
$$

Finalmente, é necessário notar que o objetivo deste capítulo foi mostrar o conteúdo que é essencial para compreender os modelos de redes complexas que serão desenvolvidos. 


\section{Modelos de redes}

As redes como área de pesquisa têm suas origens na teoria de grafos. Por volta do ano 1735, o matemático Leonard Euler apresentou sua solução sobre o problema clássico chamado as pontes de Königsberg, que consiste em sete pontes construídas para atravesar o rio Pregel da cidade de Königsberg. Cinco dessas pontes estavam conectadas com a ilha central Knelphol, as quais serviam para permitir o intercâmbio comercial na cidade. Baseado nessa situação, originou-se a pergunta: é possível atravessar por todas as pontes sem passar duas vezes pela mesma? (ver Figura 2)

Figura 2 - Grafo da estrutura das pontes de Königsberg

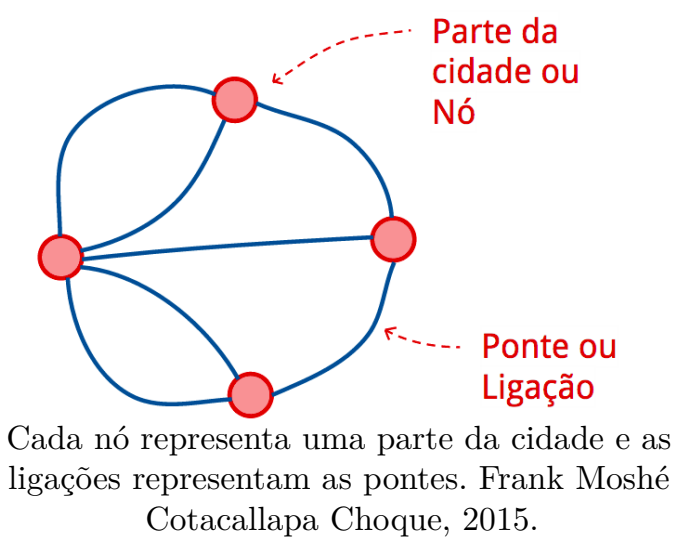

A prova que Euler desenvolveu para responder a pergunta significou um grande avanço no estudo de grafos, e deu origem a uma nova área de pesquisa. Como afirma Barabási (2013, p. 26), embora a pesquisa de redes tenha origem nos grafos, os termos usados nas duas áreas são diferentes conforme mostrado na seguinte lista.

$\begin{array}{cc}\text { Teoria de rede } & \text { Teoria de grafos } \\ \text { rede } & \text { grafo } \\ \text { nó } & \text { vértice } \\ \text { ligação } & \text { aresta }\end{array}$

Segundo Steen (2010), uma rede é uma coleção de ligações e nós na qual os nós podem estar conetados entre eles por meio de ligações (ver Figura 2). Além disso, existem diversos tipos de redes. Nas redes regulares todos os nós possuem uma quantidade igual de ligações, e quando os nós possuem ligações com todos os outros nós, a rede é nomeada como completa. Outro importante conceito é o subgrafo, que é um subconjunto de nós e ligações de outra rede inicial. Desse modo, a quantidade de ligações ou nós do subgrafo não pode ser maior que a da rede inicial. 
Embora o olho humano seja uma poderosa ferramenta para reconhecer fenômenos e estruturas das redes, ele possui limitações para trabalhar com uma quantidade maior de componentes. Além disso, a grande maioria dos pesquisadores na área de redes complexas possui interesse em redes da ordem de centena de milhares ou milhões de nós, o qual é uma limitação na visualização e interpretação pelo olho humano. Sabendo dessa limitação, foi desenvolvido a teoria de redes, que fornece diversas medidas para analisar as redes e compreender sua estrutura mesmo sem ter a sua visualização (NEWMAN, 2010; MITCHELL, 2006).

Algumas definições são necessárias antes de introduzir os modelos de redes:

- Grau: representa o número de ligações que possui um nó. Este número não necessariamente representa a quantidade de nós adjacentes, pois é possível que exista mais de uma ligação entre dois nós.

- Componente: é o conjunto de nós que possuem ligações entre eles, sendo que esse conjunto encontra-se isolado de outros nós da rede.

- Distância geodésica: é o caminho mais curto através das ligações da rede desde um nó até outro nó, sendo representado pelo número de ligações entre os dois nós.

- Diâmetro: É a distância geodésica mais longa entre dois nós, em todo o grafo.

\subsection{Propriedades}

\section{Fenômeno Small-World}

Um experimento interessante construído por Milgram (1967), conhecido mais tarde como seis graus de separação, sugeriu de modo experimental que é possível entrar em contato com qualquer pessoa ao redor do mundo através de cinco pessoas, ou seja, em seis passos. Nesse sentido, um conceito importante que emerge é o fenômeno chamado de small-world. Ele é baseado na distância geodésica $L$ entre dois nós típicos de uma rede, e o fenômeno existe quando essa distância é muito menor que qualquer potência positiva de $N$, onde $N$ é o tamanho da população; por exemplo, podemos dizer que cresce proporcionalmente ao logaritmo da quantidade $N$ de nós da rede $(L \propto \log N)$. Este fenômeno é importante de analisar por estar presente em muitas estruturas de redes reais, especialmente em redes de amizades conforme mostra Newman (2010).

Uma das formas de obter uma rede com o fenômeno small-world é o modelo proposto por Watts e Strogatz (1998). Ela é construída sobre uma rede regular, e a cada passo, um nó e uma ligação sua com outro nó $V$, é escolhida. Esta ligação é mantida na mesma posição com probabilidade $1-p$, ou sua ligação com $V$ é reconectada com probabilidade complementar com outro nó escolhido aleatoriamente. Desse modo, a distância geodésica 
quando $p=0$ é $L \sim \frac{n}{2 k}$, onde $n$ é a quantidade de nós da rede e $k$ o número de ligações por cada nó. Quando $p=1$, ou seja, quando a rede é totalmente aleatória e deixa de ser regular, a distância geodésica é $L \sim \frac{\ln (n)}{\ln (k)}$.

\subsubsection{Aglomeração}

Segundo Newman (2010), uma propriedade importante que emerge em algumas redes é o clustering ou aglomeração. Exemplificando, é uma medida presente na procura de grupos de nós que possuem ligações internamente, e em termos de redes sociais, significa que é provável que o amigo do meu amigo seja meu amigo. A formalização matemática é baseada na procura de triângulos (três nós ligados entre eles) ao longo da rede, e isso implica o valor do coeficiente de aglomeração $C$ ser

$$
C=\frac{3 \cdot \text { número de triângulos na rede }}{\text { número de nós com duas ligações }} \text {. }
$$

A multiplicação da constante 3 refere-se à normalização da equação, sendo que cada triângulo possui 3 nós; assim, é garantido que o valor de $C$ sempre estará entre 0 e 1.

\subsubsection{Distribuição de grau}

A distribuição de grau é uma função probabilística que indica a probabilidade de um nó ter um determinado grau $k$ e é denotado por $P(k)$. Para obter os valores da distribuição, é necessário calcular a probabilidade para todos os valores de $k$; desta forma,

$$
P(k)=\frac{N_{k}}{N}
$$

para uma quantidade fixa $N$, onde $N_{k}$ representa a quantidade de nós que possui $k$ ligações. Como esta medida é uma probabilidade, ela é normalizada $\left(\sum_{k=0}^{\infty} P(k)=1\right)$.

Baseado na distribuição de grau, é possível encontrar os hubs, que são grupos de nós com uma quantidade muito maior de ligações. Em termos de redes sociais, podem ser definidos como os grupos populares de amigos que possuem uma grande rede de amizades. Outro resultado importante que é obtido a partir desta medida é o grau médio de uma rede $\langle k\rangle$, que é definido como

$$
\langle k\rangle=\sum_{k=0}^{\infty} k P(k) .
$$

\subsubsection{Detecção de comunidades}

Um conceito importante é o dos clusters ou comunidades, que são subredes que possuem uma maior quantidade de ligações entre os seus nós do que entre as subredes. 
Um exemplo simples é o grupo de amigos da faculdade com outro grupo de amigos do trabalho: claramente existe uma forte interação entre os componentes de cada grupo; porém, possivelmente existe menos interação entre os componentes de grupos diferentes. Esta medida é de especial interesse porque permite entender qual é a estrutura de uma rede, e como detectar estas subredes ou comunidades é um dos temas de maior interesse na teoria de redes como mostra Dorogovtsev e Mendes (2003) e Newman (2010). Existem outras medidas adicionais que ajudam no processo de detecção de comunidades como coeficiente de aglomeração, distância geodésica, entre outros.

Baseado em algumas destas medidas e usando o conteúdo apresentado no capítulo de Princípios de probabilidade (2), introduzimos os principais modelos de redes complexas e algumas técnicas que foram desenvolvidas para obter a distribuição de grau $P(k)$ e outras medidas. Uma dessas técnicas é chamada equação mestra, que é baseada no tempo e na distribuição de grau, e que será mencionada várias vezes ao longo do texto.

\subsection{Equação mestra}

Um dos métodos usados para representar a evolução da rede ao longo do tempo é a equação mestra, que é a evolução temporal da distribuição de probabilidade e foi desenvolvida em redes complexas por Dorogovtsev e Mendes (2003). Nessa abordagem, o processo de construção da rede consiste em adicionar novos nós a cada passo de tempo, onde cada um dos nós existentes pode ser selecionado para fazer a ligação com probabilidade $\Pi$.

A rede inicia-se no tempo $t=2$ com dois nós e cada um com duas ligações entre eles. É conveniente o uso deste caso particular para facilitar os cálculos feitos posteriormente, tendo em consideração que a quantidade de ligações é proporcional ao tempo e quantidade de nós. Neste trabalho somente um único nó é adicionado a cada instante de tempo. O nó adicionado no tempo $t=3$ vai ligar a qualquer um dos nós existentes com a mesma probabilidade, $1 / 2$, de tal modo que no próximo passo de tempo, os nós $n=1,2$ e 3 não terão o mesmo grau: um deles terá três ligações, outro duas ligações, e o último nó adicionado terá uma ligação, conforme a Figura 3.

Figura 3 - Processo de construção da rede
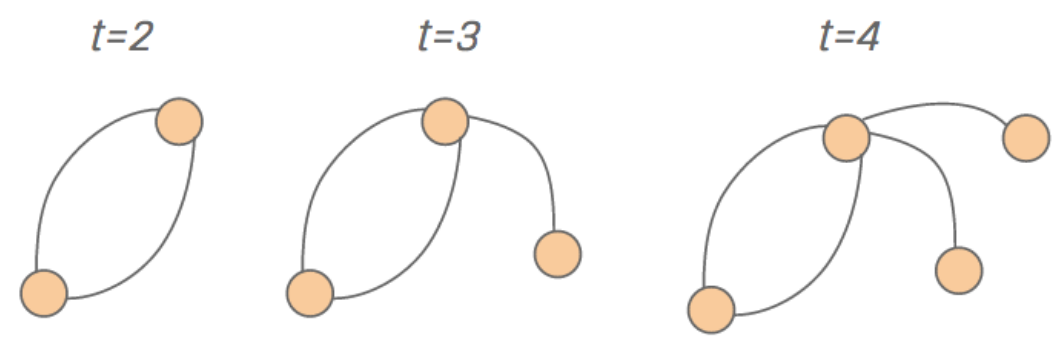

Exemplo particular da construção da rede seguindo o processo da equação mestra. Frank Moshé Cotacallapa Choque, 2015. 
Assim, generalizando a situação para qualquer tempo, no instante $t+1$ é adicionado um novo nó, que poderá fazer a ligação com qualquer nó já existente $n=1,2, \ldots, t$, com uma certa probabilidade $\Pi$, e esta probabilidade depende da regra de ligação. Nesse sentido, foram usadas duas regras: a primeira é baseada na quantidade de nós que existe na rede, onde cada um dos nós antigos possui a mesma probabilidade $\Pi(t)=\frac{1}{t}$ de receber a ligação. A segunda regra segue uma preferência de ligação segundo a quantidade de ligações que possui cada nó da rede; assim, um nó $n$ que já está na rede possui uma probabilidade de receber ligação $\Pi\left(k_{n}, t\right)=\frac{k_{n}}{2 t}$, onde $k_{n}$ é o grau do nó $n$. Se o modelo segue a primeira regra, será nomeado ao longo do texto como modelo aleatório uniforme; caso siga a segunda regra, será nomeada como modelo de Barabási-Albert, que será explicado em maior detalhe na Seção 3.5.

Seja $P(k, t)$ a distribuição de grau no tempo $t$, e seja $p(n, k, t)$ a probabilidade que o nó $n$ tenha $k$ ligações no tempo $t$. Então, $P(k, t)$ pode ser escrito como

$$
P(k, t)=\frac{1}{t} \sum_{n=1}^{t} p(n, k, t),
$$

onde o fator $\frac{1}{t}$ é uma normalização. Para definir $p(n, k, t+1)$, ou seja, conhecer a probabilidade de qualquer nó $n$ ter $k$ ligações no tempo $t+1$, serão consideradas 2 possibilidades neste trabalho, sendo que a cada instante de tempo apena um único nó é adicionado à rede:

1. No tempo $t$, o nó $n$ tem $k-1$ ligações, e a probabilidade de receber uma ligação de um novo nó é $\Pi(k-1, t)$. O novo nó liga-se com o nó $n$, passando este último a ter $k$ ligações.

2. A outra situação é quando o nó $n$ no tempo $t$ já tem $k$ ligações. Portanto, procura-se manter a mesma quantidade. Assim, a probabilidade de não fazer a ligação com o nó novo é $1-\Pi(k, t)$; portanto, no tempo $t+1$, o nó $n$ irá continuar tendo $k$ ligações.

Desse modo, a equação mestra considerando as duas possibilidades é dada por

$$
p(n, k, t+1)=\Pi(k-1, t) p(n, k-1, t)+(1-\Pi(k, t)) p(n, k, t) .
$$

\subsection{Modelo aleatório uniforme}

Neste modelo de rede, a probabilidade de ligação depende da quantidade de nós que existe na rede, sendo a mesma probabilidade $\Pi=\frac{1}{t}$ para todos eles. Ver Figura 4.

Assim, desenvolvendo a equação mestra, finalmente obtemos o valor da distribuição de grau

$$
P(k)=2^{-k}
$$


Figura 4 - Processo de construção da rede Aleatória Uniforme
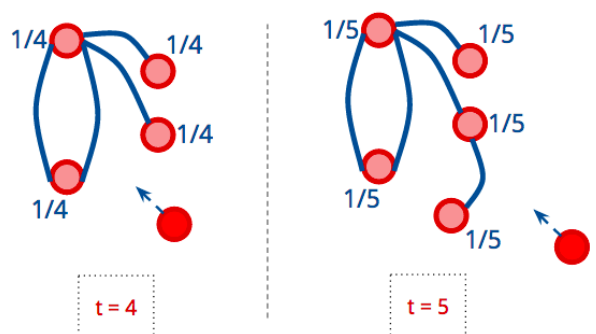

Exemplo do processo de construção de uma rede aleatória uniforme. Na imagem mostra-se a variação da rede para o tempo $t=4$ e $t=5$, onde as frações são referentes à probabilidade de ligação. Frank Moshé Cotacallapa Choque, 2015.

A média dos graus da rede é

$$
\langle k\rangle=\sum_{k=1} k P(k)=2
$$

conforme esperado, se temos em consideração que, a cada passo de tempo, cada ligação adiciona uma ligação em dois nós, isto é,

$$
\langle k\rangle=\frac{2 t}{t}=2 .
$$

Os procedimentos para encontrar as distribuição de grau e o grau médio são apresentados com maiores detalhes no Apêndice A.

\subsection{Modelo de Erdős-Rényi}

Um dos primeiros estudos sobre redes aleatórias é devido aos matemáticos Erdös e Rényi (1960). Para construir a rede, eles usaram o método probabilístico na construção das ligações entre uma quantidade fixa de nós.

Existem diversas variações deste modelo. Um deles é construído começando com uma quantidade de $n$ de nós e $m$ ligações; este modelo é nomeado como $G(n, m)$. Para obter a rede, é necessário construir todas as combinações possíveis de estruturas de rede que possuam $n$ nós e $m$ ligações, sendo que uma dessas estruturas é escolhida aleatoriamente. Outra forma de construção da rede do modelo de Erdős-Rényi é nomeada $G(n, p)$, que também tem uma quantidade fixa $n$ de nós, e existe uma probabilidade $p$ de fazer a ligação entre dois nós; deste modo, a quantidade de ligações encontra-se na faixa de 0 até $\left(\begin{array}{l}n \\ 2\end{array}\right)$. No processo de construção do modelo $G(n, p)$, cada nó é ligado com outro segundo probabilidade $p$, sendo que esse processo é repetido para todos os nós. Deste modo, se $p=1$, então o grafo é completo, e no caso contrário $p=0$, a rede não possui ligações. 
Assim, o valor da distribuição de grau para este modelo é uma distribuição binomial. Considerando o grau médio finito e $n \rightarrow+\infty$, obtemos a distribuição de Poisson, na qual a quantidade de nós $n$ é suficientemente grande e $p$ o suficientemente pequeno para que $c$ seja constante, isto é, $c=(n-1) p=$ cte.

Desse modo,

$$
P(k)=\left(\begin{array}{c}
n-1 \\
k
\end{array}\right) p^{k}(1-p)^{n-1-k}
$$

que tomado os limites acima, pode ser transformado em

$$
P(k)=\frac{c^{k} e^{-c}}{k !} .
$$

Os procedimentos usados podem ser vistos no Apêndice B.

O estudo do modelo de Erdős-Rényi tem especial importância na análise dos próximos modelos ao permitir mostrar suas propriedades e analisar como funciona uma rede aleatória.

\subsection{Modelo de Barabási-Albert}

O modelo de Barabási e Albert (1999) é fundamentado no tempo e a quantidade de ligações dos nós, e estabelece duas características principais: crescimento da quantidade de nós ao longo do tempo (redes crescentes) e ligações preferenciais (probabilidade de um nó receber conexão proporcional ao seu grau). Isto faz com que a rede de Barabási-Albert (nomeado de BA ao longo do texto) seja mais próximo das redes reais que a rede de Erdős-Rényi. Para mostrar isso, foram analisadas diversas redes de amizades, atores, colaboração científica, entre outros, conforme Barabási et al. (2002), Albert e Barabási (2002) e Barabási (2013).

Para obter a distribuição de grau, um dos métodos usados é através de equacões mestras. Assim, a construção do modelo com preferência de ligação e usando as equações mestras pode ser desenvolvido a partir da equação mestra (3.5), onde $\Pi$ representa a probabilidade de um nó ter $k$ ligações no tempo $t$. Continuando com a construção do modelo, é adotado como valor da probabilidade de ligação $\Pi(k, t)=\frac{k}{2 t}$, que mostra que existe uma preferência de escolha com os nós de maior grau $k$ (ver Figura 5).

No processo de construção da rede, em cada unidade de tempo são adicionados um novo nó e uma ligação. Considerou-se como condição inicial a existência de dois nós com duas ligações entre elas no instrante $t=2$ como na rede anterior (ver Figura 3). Espera-se que o resultado final não seja afetado por esta estrutura inicial adotada. 
Figura 5 - Processo de construção da rede de Barabási-Albert
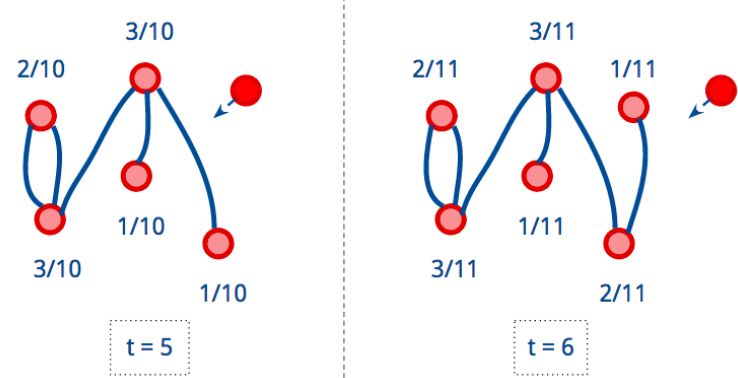

Exemplo do processo de construção de uma rede de Barabási-Albert. Na imagem, mostra-se a variação da rede nos tempos $t=5$ e $t=6$, onde as frações indicam a probabilidade com a qual o novo nó (em vermelho escuro) ligaria com cada um dos nós. Frank Moshé Cotacallapa Choque, 2015.

Desse modo, chegamos no seguinte resultado da distribuição de grau,

$$
P(k)=\frac{4}{k(k+1)(k+2)},
$$

e para $k \gg 1$, obtemos a distribuição do grau como sendo $P(k) \sim k^{-3}$. O procedimento para chegar neste resultado encontra-se em maior detalhe no Apêndice C.

Outro método para obter o mesmo resultado é a Transformada Z, que é desenvolvida no Apêndice E.

\subsection{Diferenças entre os modelos}

Os dois modelos (Barabási-Albert e Erdős-Rényi) apresentam comportamentos diferentes. Enquanto BA tem uma pequena quantidade de nós com grau grande, no modelo ER é exponencialmente raro observar nós com essa característica. Além disso, no modelo BA a maior parte da rede é formada por nós com poucas ligações; no entanto, no modelo ER a maior parte concentra-se nos nós que possuem graus próximos à média (ver Figura $6)$.

Observa-se na Figura 7, onde a distribuição de grau do modelo BA é mostrado em escala logaritmica, o comportamento de lei de potência na sua distribuição de grau, além de uma quantidade considerável de nós com poucas ligações, enquanto no modelo ER a maior parte encontra-se próximo do grau médio e próximo a ele.

Como mostra Newman (2010) e Barabási (2013), a rede ER é melhor distribuída em relação à quantidade de ligações que possui. No entanto, ela carece de nós que tenham um domínio abrangente na rede, como acontece no caso da rede BA.

Ver código da geração das redes BA e ER no apêndice D. 
Figura 6 - Modelos de rede: Barabási-Albert e Erdös-Rényi

(a) Rede deBarabási-Albert

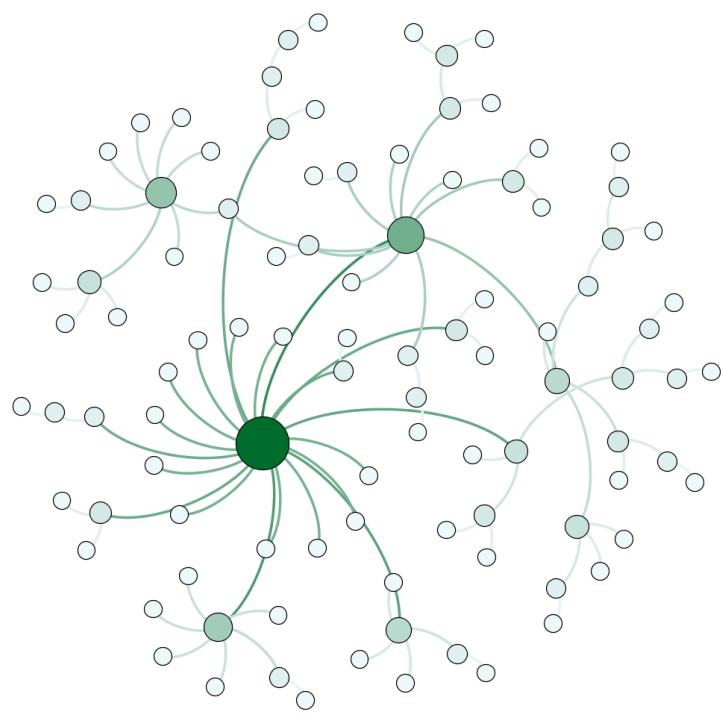

(b) Rede de Erdös-Rényi

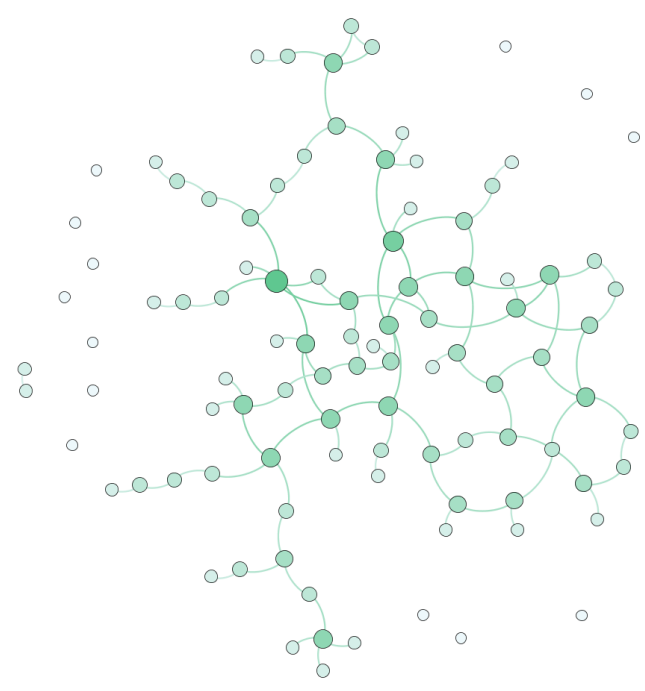

Cada modelo possui 100 nós e a cor e o tamanho são proporcionais ao grau do nó. Frank Moshé Cotacallapa Choque, 2015.

\subsection{Epidemia}

A propagação é um termo usado em diferentes situações, tais como propagação de informação, de doenças, de boatos, entre outros. Um dos casos especiais é a propagação de doença, em que um determinado momento pode virar uma epidemia, criando uma transição na propagação. Porém, na literatura de redes complexas, o termo epidemia regularmente refere-se ao processo de propagação da doença ou qualquer outro elemento, sendo assim, um termo mais abrangente como é mostrado por Newman, Barabási e Watts (2006). Adicionalmente, nesse processo foram introduzidas diversas variações nas regras de contágio como a possibilidade de reinfecção, interação da população, entre outros.

A diferença entre os modelos desenvolvidos sobre epidemia é basicamente em relação à estrutura ou sobre as regras de propagação. Um dos principais processos de propagação é o SIR (Suscetível, Infectado e Recuperado) e suas variações (SI, SIS, SIRS), segundo Newman (2010). Além disso, Newman (2003) dá exemplos de muitos modelos reais de epidemia que converge para algum desses processos e que foram estudados amplamente. Doenças como sarampo e catapora em sua grande maioria têm um comportamento SIR; outras mais comuns como a gripe seguem o processo SIRS; já outras doenças com maior dificuldade de combater até a atualidade como o vírus do HIV seguem o comportamento do SI.

Um dos artigos sobre propagação de epidemias em redes é devido a Ball, Mollison e Scalia-Tomba (1997), que de uma abordagem matemática desenvolveram esquemas de 
Figura 7 - Comparação das distribuições de grau
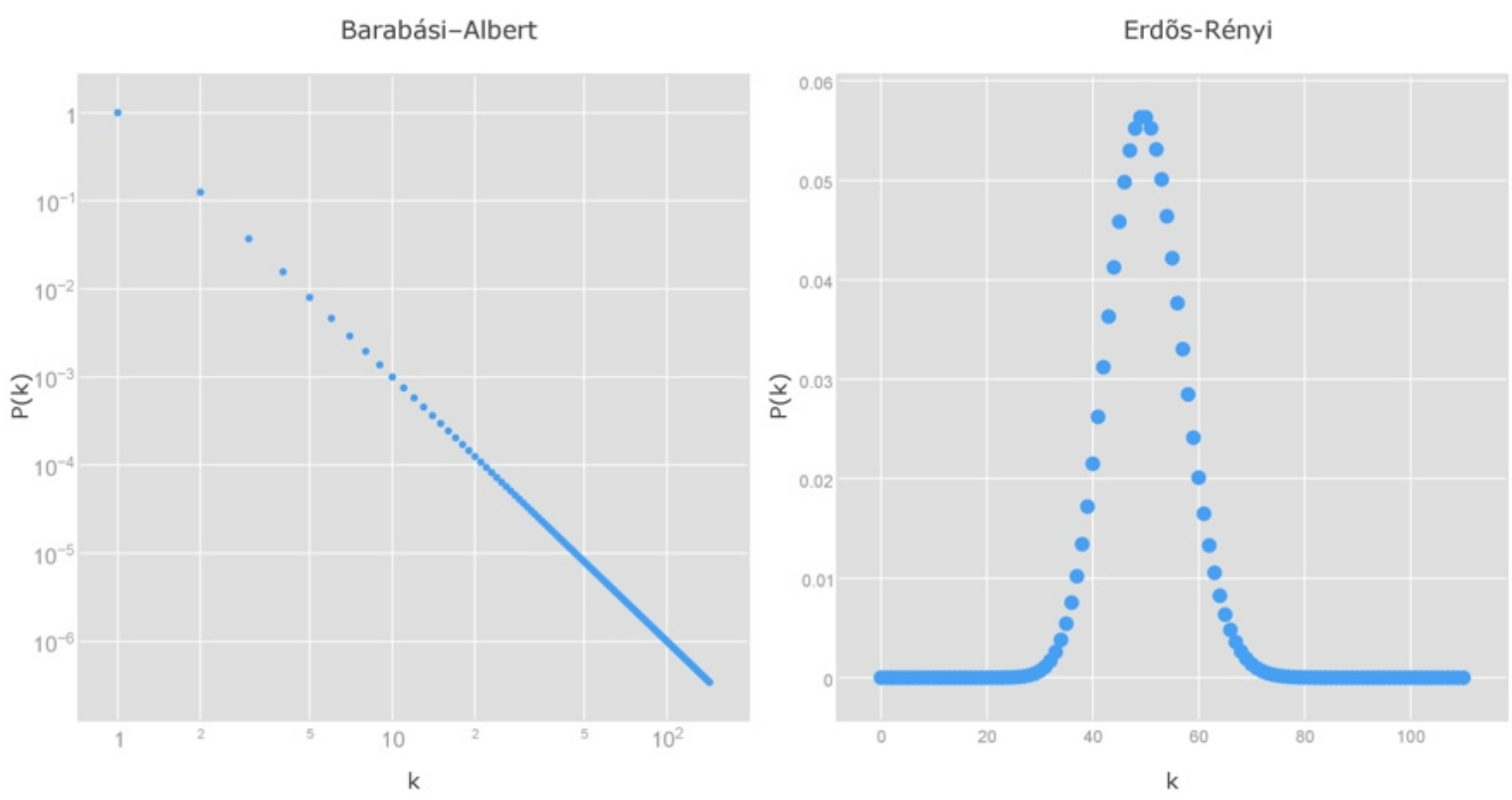

Gráfico comparativo $P(k) \times k$ entre os dois modelos. Notar que o gráfico da distribuição de Barabási-Albert está em escala log-log. Por outro lado, a distribuição de Erdös-Rényi está sobre os eixos lineares. Frank Moshé Cotacallapa Choque, 2015.

propagação para modelos de rede específicos, mas as técnicas podem ser aplicadas para outros modelos. Esse modelo possui dois níveis de ação (global e local), sendo que cada nó pertence à rede global e também a uma subrede local. Desse modo, é possível analisar o caso de uma epidemia que é espalhada localmente (entre nós da mesma subrede) ou globalmente (com nós de outras subredes), onde a epidemia local possui maior probabilidade de propagação. Um dos principais resultados mostrou que quando a epidemia se propaga nas subredes, ele gera uma eclosão em toda a rede de forma fácil, mesmo quando a probabilidade de propagação entre subredes é baixa. Outro modelo é o desenvolvido por Keeling (1999), na qual a propagação em redes foi analisada a partir de uma abordagem baseada em equações diferenciais seguindo o processo SIR, e mostrou que uma pequena parte da população precisa ser vacinada para evitar uma epidemia caso exista um coeficiente de aglomeração alto na rede.

Embora a epidemia seja um fenômeno de propagação importante, outros tipos de propagação também foram analisados. Pastor-Satorras e Vespignani (2001) desenvolveram uma rede scale-free seguindo o processo SIS, dando especial ênfase na propagação de vírus para computadores. Um dos resultados mais interessantes obtidos mediante simulação é o fato que o vírus nunca desaparece da rede, mesmo quando a quantidade de nós infectados caia exponencialmente. Outro resultado é que a propagação do vírus não apresenta um limiar de transição entre os estados (Suscetível ou Infectado) dos nós.

Outro tipo de propagação que também foi analisado é sobre alguns tipos de informações: boatos, opiniões e publicidade. Esta abordagem se diferencia das epidemias 
porque para espalhar um conteúdo é preciso estar em contato com uma quantidade mínima de elementos para mudar sua informação. Assim, há tentativas para entender como um determinado livro, música, ou qualquer outro conteúdo se torna popular. Desse modo, Watts (2002) apresentou um modelo de rede onde cada nó representa uma pessoa que possui um limiar da quantidade de vizinhos necessário para adotar um certo conteúdo. Um dos resultado apresentados é que a propagação depende essencialmente da quantidade de nós com baixo limiar, ou seja, quando existe uma quantidade necessária de nós que adotou o conteúdo, praticamente é garantido que ela será espalhada na maior parte da rede.

Um dos conceitos importantes em epidemia é a robustez, isto é, quanta resiliência o sistema possui frente às possíveis falhas na rede e como ela afeta na propagação. No artigo apresentado por Barabási, Albert e Jeong (1999) é feita uma análise da resiliência do modelo de rede small-world e scale-free, onde se conclui que as redes que seguem uma distribuição scale-free são mais robustas que a rede aleatória Erdös-Rényi, mas menos robustas a ataques contra nós específicos que possuem uma alta concentração de ligações. Outra abordagem similar foi apresentada por Cohen et al. (2000), onde desenvolveu-se modelos matemáticos para obter resultados analíticos da resiliência de modelos de redes aleatórias com distribuição de grau escolhida arbitrariamente. Neste modelo, os nós são excluídos aleatoriamente e observou-se que quando são excluídos uma quantidade $p$ de nós da rede, esta continua mantendo um comportamento aleatório. Quando $p$ alcança um determinado ponto crítico, os nós da rede ficam isolados. Em testes realizados pelos mesmos autores, comprovou-se que uma rede com distribuição de grau power-law apresenta grande resiliência contra ataques aleatórios. 


\section{Modelos de propagação de epidemia}

\subsection{Introdução}

Tal como foi apresentado no capítulo anterior, o processo de contágio em epidemias está presente em diversos tipos de ambientes, e uma delas são as redes. No intuito de compreender o fenômeno, ao longo deste capítulo procura-se mostrar os resultados analíticos e computacionais da propagação sobre dois modelos: rede aleatória uniforme (seção 3.3) e a rede de Barabási-Albert (seção 3.5).

Nesses modelos, analisou-se o caso de epidemia seguindo o processo Suscetível Infectado (SI), sendo que esse processo é também usado na propagação de outros elementos como informação, rumores, ou doenças sem cura. É claro que cada um desses modelos tem suas próprias características em relação ao tempo de propagação, estrutura da rede, regras do processo de propagação, entre outros.

Com o propósito de abstrair a realidade e obter resultados analíticos, construiu-se cinco modelos de rede, dos quais quatro foram obtidos mediante modelamento matemático em conjunto com cinco simulações computacionais. Todos os modelos aqui apresentados possuem um processo de construção ao longo do tempo usando equações mestras a tempo discreto como abordagem principal. Desse modo, a cada passo da unidade de tempo é adicionado um novo nó e uma ligação, sendo que também é inserido a decisão de contágio junto com eles.

Quando um novo nó ingressa na rede, ele possui uma probabilidade de ligação П e sobre essa ligação é executada a decisão do contágio, ou seja, existem duas decisões para cada novo nó: a) com quem fazer a ligação? e b) posso propagar a doença através dessa ligação? Como consequência, cada ligação possui dois estados: com contágio e sem contágio.

Figura 8 - Processo de contágio

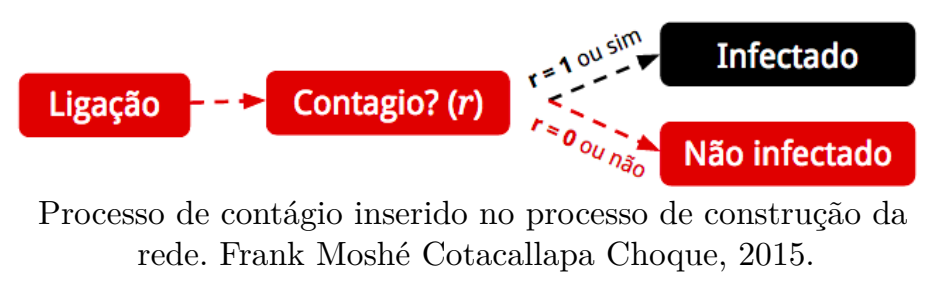

A decisão de contágio é denotada por $r \in\{0,1\}$, onde $r=1$ significa que existe contágio e $r=0$ o caso contrário, conforme mostrado na Figura 8. Além disso, a proporção de quantas ligações recebe o contágio é governado pelo valor de $c \in[0,1]$, que é definida 
pela seguinte função

$$
\mathcal{P}(r)=c \delta_{r, 1}+(1-c) \delta_{r, 0}, \quad c \in[0,1] \subset \mathbb{R}
$$

onde $\delta_{i, j}$ é função delta de Kronecker, que é definida como $\delta_{i j}=1$, quando $i=j$, e $\delta_{i j}=0$, quando $i \neq j$.

Portanto, quanto maior o valor de $c$, maior a probabilidade de contágio. Como resultado do desenvolvimento do modelo de propagação da epidemia usando equações mestras, a distribuição de grau vira uma distribuição reduzida, tendo em consideração que o modelo da propagação é uma subrede do modelo de rede original e portanto não normalizada; este ponto será abordado ao longo das próximas seções. Assim, a notação da distribuição da propagação da epidemia ao longo dos modelos será denotada como $\tilde{P}_{r}(k)$.

A primeira abordagem é baseada no contágio fixo, isto é, o valor da decisão de contágio é o mesmo para todas as ligações. Portanto, a doença é propagada em todas as ligações da rede, $r=1$, ou nenhuma delas é contagiada $(r=0)$. Para esta abordagem é necessário notar que foram estabelecidas duas variações no procedimento para obter a distribuição da propagação da epidemia.

As duas variações inseridas na primeira abordagem têm sua origem na metalurgia, e também foram exploradas na teoria de vidros de spin no domínio da física estatística segundo Mézard, Parisi e Virasoro (1987). Essas abordagens são nomeadas como temperada(quenched) e recozida(annealed). A variação temperada consiste na geração de vários modelos nos quais o valor da decisão de contágio $r$ é constante em cada rede construída. Dessa forma, algumas redes possuem todas as ligações contagiadas e outras ficam sem nenhum contágio; a distribuição da epidemia com essa variação é a média de todos os modelos gerados $\left\langle\tilde{P}_{r}(k)\right\rangle$. Por outro lado, a variação recozida consiste na geração de várias decições de contágio, para depois obter a sua média $(\langle r\rangle)$, e substituir esse valor na equação mestra, para finalmente obter a distribuição da epidemia $\tilde{P}_{\langle r\rangle}(k)$. A diferença entre as abordagens será mostrada nas próximas seções.

A segunda abordagem é baseada no contágio variável, em que a cada unidade de tempo a decisão de contágio $r$ pode mudar. Esta abordagem foi desenvolvida sobre as duas estruturas (Barabási-Albert e Aleatória Uniforme). A terceira abordagem foi desenvolvida apenas usando recursos computacionais, seguindo o mesmo procedimento da segunda abordagem; porém, apenas sobre a rede de Barabási-Albert e inserindo uma mudança na preferência de ligação. Enquanto na rede BA a preferência de ligação é proporcional à quantidade de ligações que possui cada nó (preferência geral), nesta abordagem, a preferência de ligação é proporcional apenas à quantidade de ligações contagiadas (preferência epidêmica), conforme mostrado na Figura 9.

Finalmente, a lista dos modelos desenvolvidos é apresentada na Figura 10. 
Figura 9 - Preferência geral e preferência epidêmica

\begin{tabular}{|c|c|}
\hline $\begin{array}{c}\text { Pref. Geral } \\
=3 / 8\end{array}$ & $\begin{array}{c}\text { Pref. Epidêmica } \\
=1 / 4\end{array}$ \\
\hline $\begin{array}{c}\text { Grau total da } \\
\text { rede: } 8\end{array}$ & $\begin{array}{c}\text { Grau total das } \\
\text { infecções: } 4\end{array}$ \\
\hline Grau do nó: 3 & Grau do nó: 1 \\
\hline
\end{tabular}

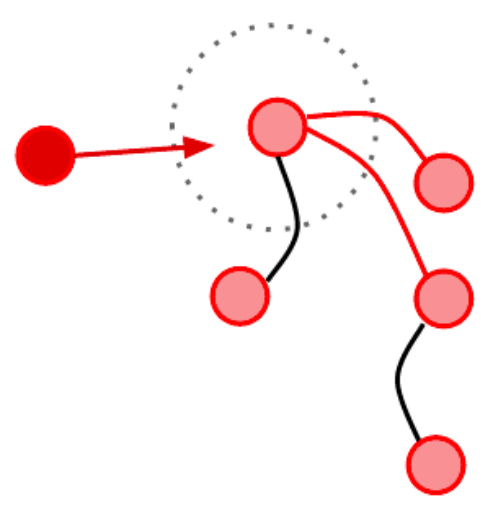

Diferença da preferência geral e preferência epidêmica. Frank Moshé Cotacallapa Choque, 2015.

Figura 10 - Lista comparativa de modelos

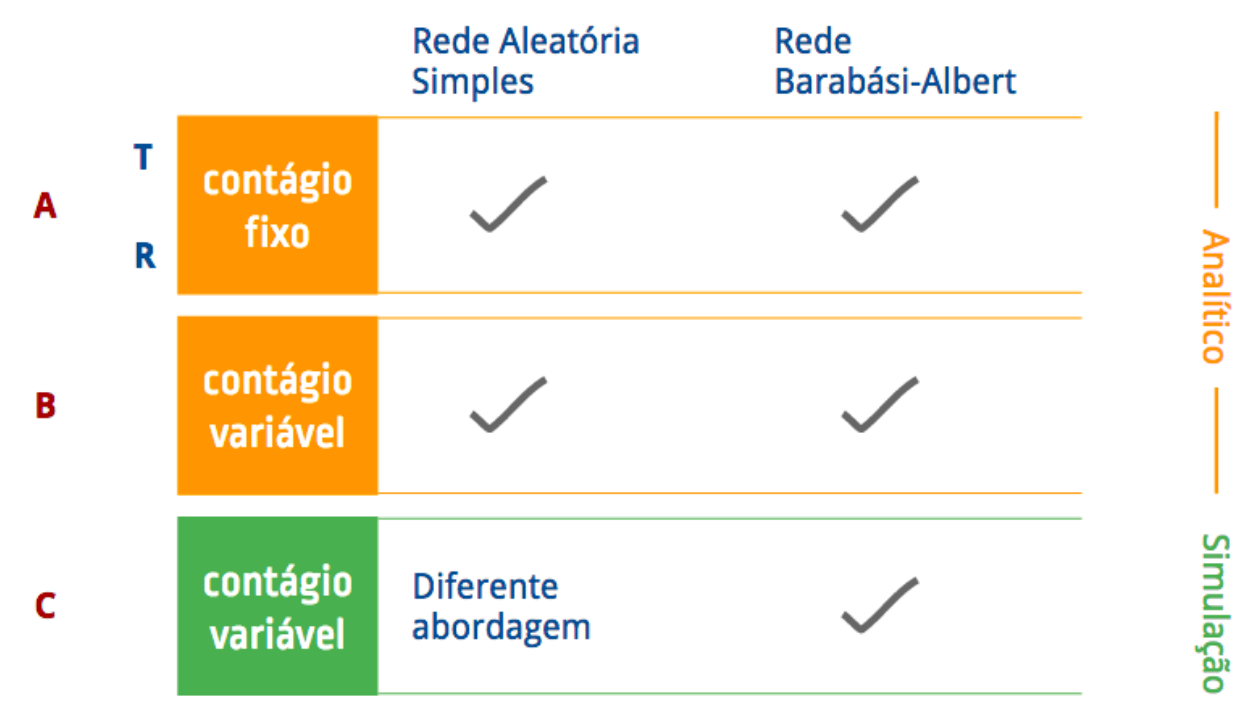

Lista dos modelos desenvolvidos no texto, sendo três abordagens diferentes sobre duas estruturas de rede. Notar que a primeira abordagem possui duas variações, temperada(T) e recozida(R) . Frank Moshé Cotacallapa Choque, 2015.

\subsection{Modelo A ou contágio fixo}

Este primeiro modelo é a abordagem fixa de $r$, e é desenvolvido sobre a rede de Barabási-Albert e a rede aleatória uniforme. Os desenvolvimentos técnicos são apresentados no apêndice F.

A equação mestra sobre a rede BA é

$$
p_{r}(n, k, t+1)=r\left[\frac{k-1}{2 t}\right] p_{r}(n, k-1, t)+\left[1-\frac{k}{2 t}\right] p_{r}(n, k, t) .
$$

Do mesmo modo, na rede aleatória uniforme, a equação mestra após inserir $r$ é da 
forma

$$
p_{r}(n, k, t+1)=r\left[\frac{1}{t}\right] p_{r}(n, k-1, t)+\left[1-\frac{1}{t}\right] p_{r}(n, k, t) .
$$

Da equação (4.2) e (4.3), temos duas abordagens possíveis, onde cada uma traz resultados diferentes que serão analisadas com maior detalhe. É necessário notar que a variável inserida $r$ muda o comportamento da função $p_{r}$.

\subsubsection{Epidemia recozida sobre a rede Barabási-Albert}

Seguindo o processo recozido, são gerados vários valores da decisão de propagação $r$ para depois obter a sua média. Desse modo, $r \rightarrow\langle r\rangle$, e é esse valor que é inserido na equação mestra

$$
p_{r}(n, k, t+1)=\langle r\rangle\left[\frac{k-1}{2 t}\right] p_{r}(n, k-1, t)+\left[1-\frac{k}{2 t}\right] p_{r}(n, k, t),
$$

para finalmente obter a distribuição da propagação da rede de epidemia

$$
\tilde{P}_{\langle r\rangle}(k)=\frac{4 c^{k}}{k^{3}}
$$

Para maior detalhe, ver os procedimentos para esta abordagem do modelo A no apêndice F.

A figura 11 mostra um exemplo da distribuição de grau uma rede seguindo o comportamento recozido para valores diferentes valores de $c=\{1,0.75,0.5$ e 0.25$\}$.

\subsubsection{Epidemia temperada sobre a rede de Barabási-Albert}

Na segunda variação, seguindo o processo temperado, são geradas diferentes construções da rede para assim obter o valor médio da distribuição de propagação $\left\langle\tilde{P}_{r}(k)\right\rangle$. Em cada rede gerada é escolhido um dos valores possíveis da decisão de propagação $r$, como mostrado na Figura 8. Portanto, em algumas redes todas as ligações terão $r=1 \mathrm{e}$, em outras, $r=0$; o resultado final é a média de todas essas realizações, e a distribuição da rede de propagação é dada por

$$
\left\langle\tilde{P}_{r}(k)\right\rangle=\frac{4 c}{k^{3}}
$$

Para maior detalhe, ver os procedimentos no apêndice F.

Dois exemplos de possíveis redes que representam esta abordagem são as figuras 12a e 12b, onde as linhas em forma de traço representam as ligações da rede sem contágio e as linhas completas indicam contágio. 
Figura 11 - Epidemia recozida no modelo de Barabási-Albert

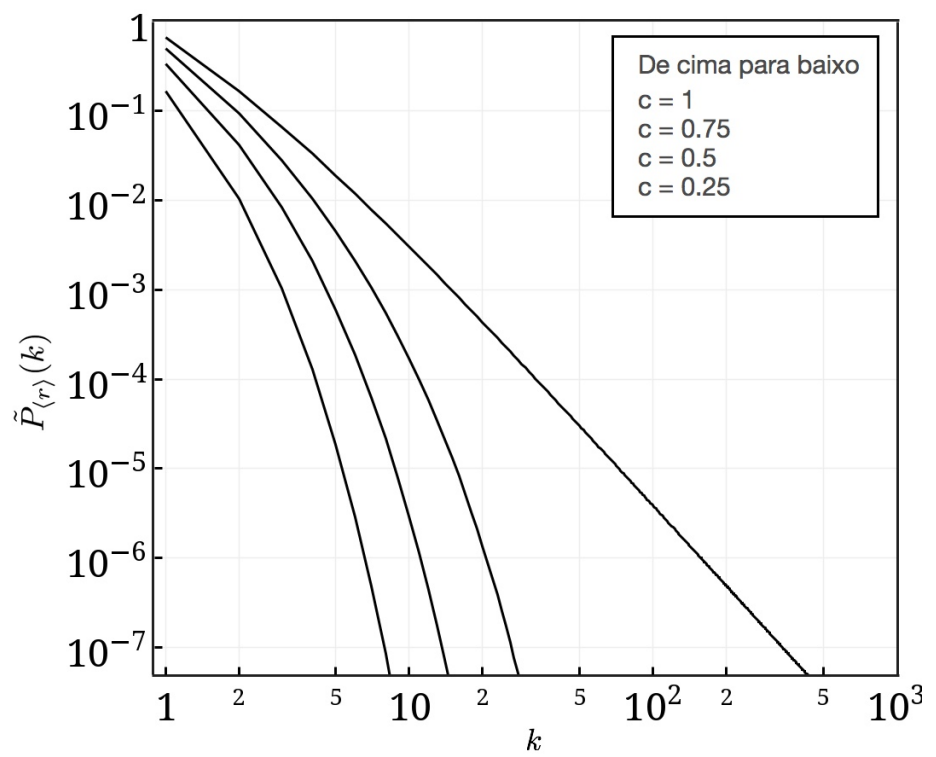

A figura mostra qual é o comportamento da distribuição de grau reduzida na rede mediante a distribuição de grau da epidemia para diferentes valores de $c$. Frank Moshé Cotacallapa Choque, 2015.

Figura 12 - Epidemia temperada no modelo de Barabási-Albert

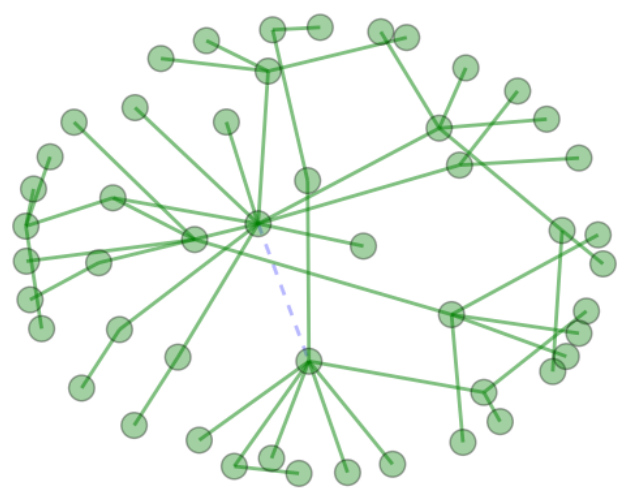

(a) Rede de Barabási-Albert com $r=1$

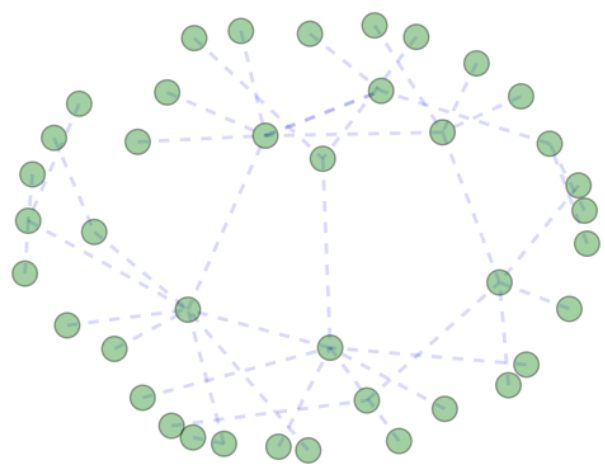

(b) Rede de Barábasi-Albert com $r=0$

Redes quando o valor de $r$ possui valores 1 ou 0. Frank Moshé Cotacallapa Choque, 2015.

Além disso, usando recursos computacionais, foram simuladas 1000 redes usando 10000 nós cada uma seguindo o comportamento temperado. A distribuição da epidemia considerando $\mathrm{c}=\{1,0.75,0.5$ e 0.25$\}$ é mostrado na Figura 13, e a distribuição da rede da epidemia segundo a equação (4.6), na Figura 14.

\subsubsection{Discussão}

É necessário notar que as duas variações acima fornecem resultados diferentes. Das equações (4.5) e (4.6) observamos uma diferença no comportamento das duas redes: 
Figura 13 - Distribuição da epidemia temperada na rede Barabási-Albert mediante simulação

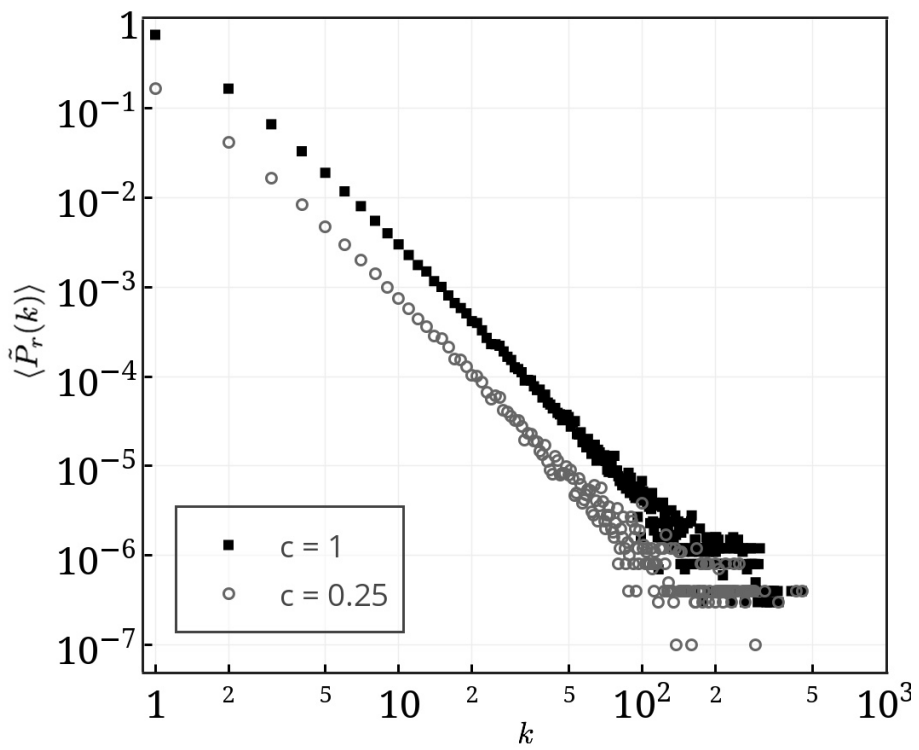

Distribuições de grau da rede de epidemia para diferentes valores de $c$ seguindo a abordagem temperada. Frank Moshé Cotacallapa Choque, 2015.

Figura 14 - Distribuição da epidemia temperada no modelo de Barabási-Albert - resultado analítico

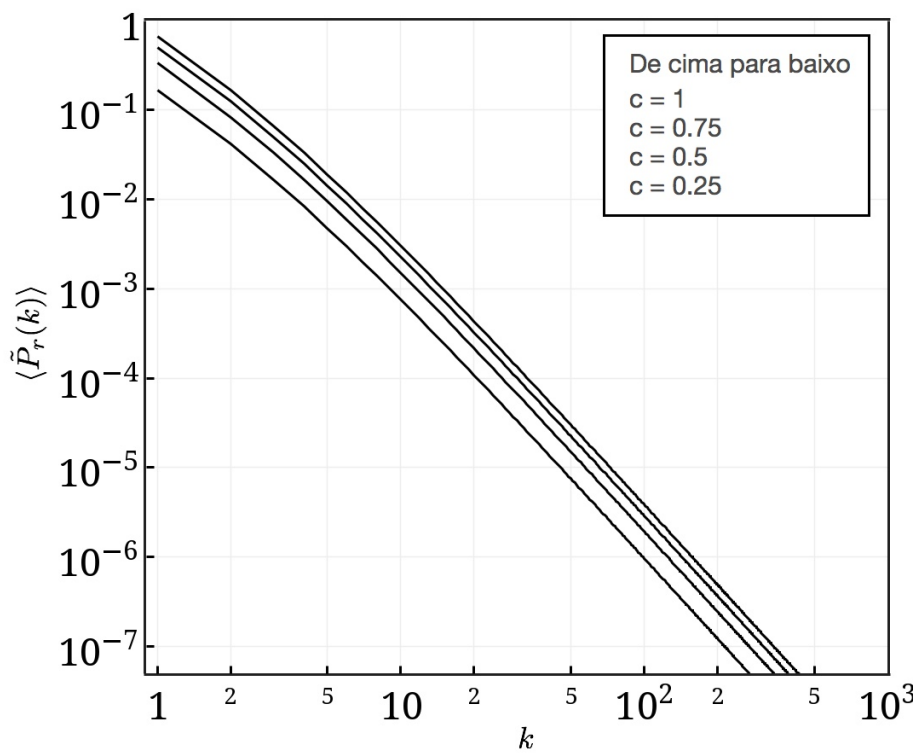

Distribuições de grau da rede de epidemia para diferentes valores de $c$ seguindo a abordagem temperada. Frank Moshé Cotacallapa Choque, 2015.

quando consideramos a abordagem recozida, a rede possui valores menores de propagação comparado com a abordagem temperada. Isso significa que o desenvolvimento da rede sobre o valor médio da decisão de contágio tem um menor desempenho para propagar comparado com a média do desenvolvimento da rede usando diferentes decisões de contágio.

É necessário notar que no caso da epidemia recozida sobre a rede BA, quando 
Figura 15 - Distribuição da epidemia temperada e recozida no modelo da rede de BarabásiAlbert - resultado analítico

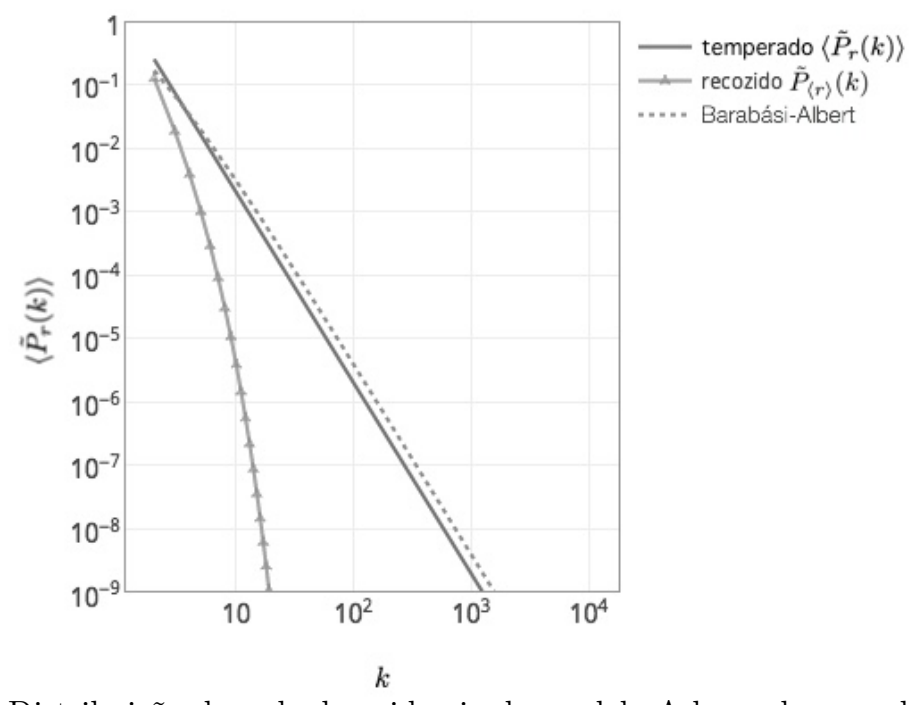

Distribuição da rede de epidemia do modelo A baseado na rede de Barabási-Albert usando $c=0.5$ nas abordagens temperada e recozida. Frank Moshé Cotacallapa Choque, 2015

inserido a decisão de contágio, o desempenho da rede para propagar muda de forma deixando de possuir um comportamento scale-free, diferentemente das outras abordagens, que mantém a mesma forma até para valores diferentes de $c$, como mostra a figura 15.

Como as redes scale-free representam alguns modelos de rede reais Barabási (2002), é natural o interesse em analisar este tipo de modelos em diferentes cenários. Nesse sentido, Bollt e Ben-Avraham (2005) analisaram em 2005 a propagação neste tipo de rede com a abordagem da caminhada aleatória, mostrando que as redes scale-free possuem uma propagação rápida. No mesmo ano, considerando que existem diversas pesquisas de propagação baseadas em redes com abordagem temperada, Stauffer e Sahimi (2005) simularam diferentes modelos scale-free com a abordagem recozida usando o caminho aleatório como modo de propagação, considerando que embora o processo temperado seja interessante, a abordagem recozida é a mais próxima da realidade.

\subsubsection{Epidemia recozida sobre a rede aleatória uniforme}

Seguindo o processo recozido, a variável $r$ é inserida na equação mestra como

$$
p_{r}(n, k, t+1)=\langle r\rangle\left[\frac{1}{t}\right] p_{r}(n, k-1, t)+\left[1-\frac{1}{t}\right] p_{r}(n, k, t),
$$

de onde se pode obter a distribuição da propagação da epidemia

$$
\tilde{P}_{\langle r\rangle}(k)=c^{k} 2^{-k} .
$$


Ver detalhes técnicos no apêndice F.

Baseado na equação (4.8), é gerado a Figura 16 para valores de $c=\{1,0.75,0.5$ e 0.25$\}$.

Figura 16 - Distribuição da epidemia recozida no modelo aleatório uniforme - resultado analítico

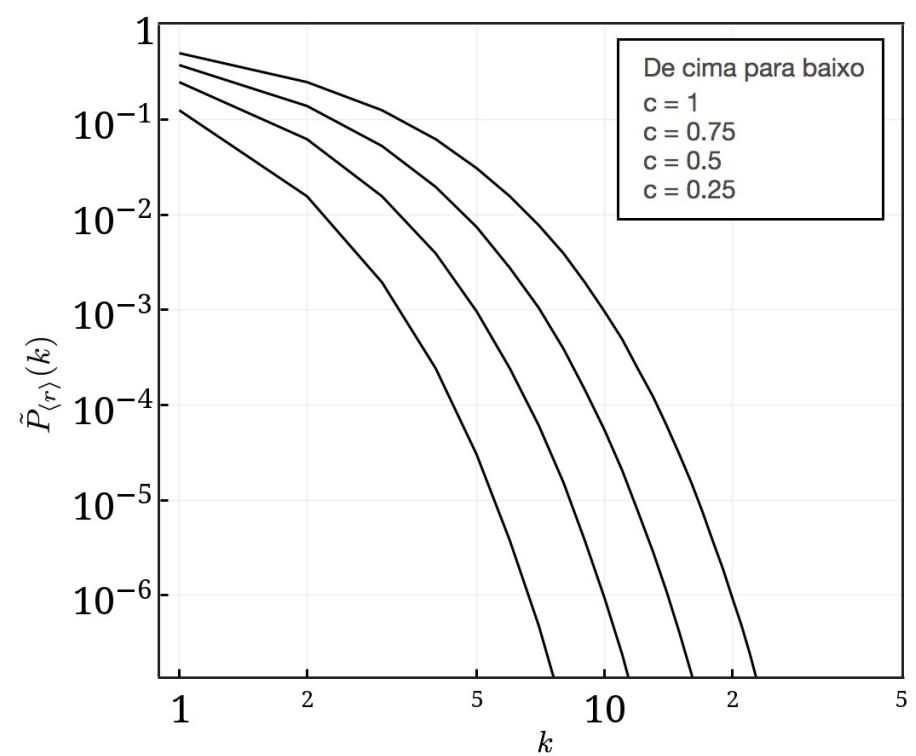

Distribuição da da rede de epidemia do modelo A baseado na rede aleatória uniforme usando diferentes valores para $c$ e a variação recozida. Frank Moshé Cotacallapa Choque, 2015.

\subsubsection{Epidemia temperada sobre a rede aleatória uniforme}

Seguindo a variação temperada, do mesmo modo que o procedimento adotado na Seção 4.2.2, é obtido o valor médio da distribuição de propagação sobre uma rede aleatória uniforme a partir da equação mestra (4.3). Assim, obtemos

$$
\left\langle\tilde{P}_{r}(k)\right\rangle=c 2^{-k}
$$

A Figura 17 mostra a equação (4.9) para diferentes valores de $c$. Para maiores detalhes, ver os procedimentos no apêndice $\mathrm{F}$

Além disso, usando recursos computacionais, simulou-se 1000 redes, e cada um deles com 10000 nós para diferentes valores possíveis de $c$, sendo a Figura 18 resultado dessas simulações.

\subsubsection{Discussão}

Como no mesmo caso da discussão da seção 4.2.3, a variação temperada possui melhor desempenho na propagação da epidemia. 
Figura 17 - Distribuição da epidemia temperada no modelo aleatório uniforme - resultado analítico

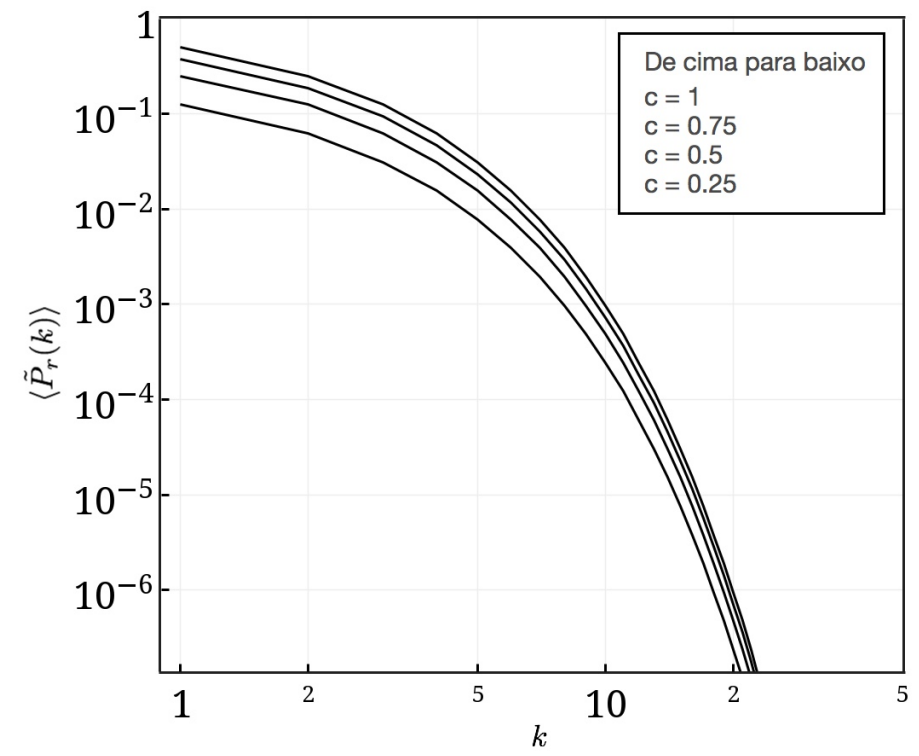

Distribuição da da rede de epidemia do modelo A baseado na rede aleatória uniforme usando a variação temperada e diferentes valores para $c$. Frank Moshé Cotacallapa Choque, 2015 .

A Figura 19 mostra ambas variações (temperada e recozida) sobre a rede aleatória uniforme, sendo elas geradas a partir das equações (4.8) e (4.9).

O decaimento da variação recozida, onde $\tilde{P}_{\langle r\rangle}(k)=c^{k} 2^{-k}$, mostra que a quantidade de nós contagiados é menor que a abordagem temperada, na qual $\left\langle\tilde{P}_{r}(k)\right\rangle=c 2^{-k}$ para $c>0$.

No entanto, no intuito de inserir outras abordagens durante o processo de contágio, optou-se por mudar a forma que a decisão de contágio é inserida na equação. Desse modo, no próximo modelo a variável de decisão $r_{t}$ não será a mesma em todas as ligações, e ela pode mudar a cada unidade de tempo, levando a algumas ligações serem contagiadas e, outras, não.

\subsection{Modelo B ou contágio variável}

Este modelo é de especial importância, pois permite desenvolver a decisão de propagação de forma independente para cada tempo, lembrando que a cada unidade tempo é também inserido um novo nó, permitindo assim que cada nova ligação possa adotar diferentes valores de contágio. Desse modo, a distribuição de probabilidade de contágio é dada por

$$
\mathcal{P}\left(r_{t}\right)=c \delta_{r_{t}, 1}+(1-c) \delta_{r_{t}, 0}, \quad c \in[0,1] \subset \mathbb{R} .
$$


Figura 18 - Distribuição da epidemia temperada no modelo aleatório uniforme - resultado da simulação

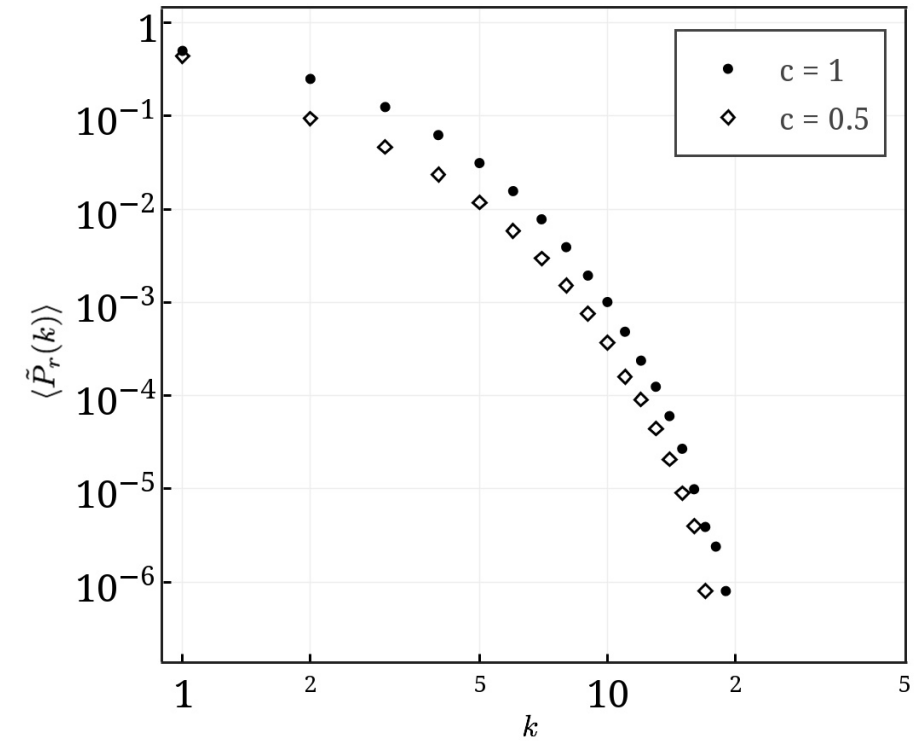

Distribuição da rede de epidemia do modelo A baseado na rede aleatória uniforme usando a abordagem temperada e diferentes valores para $c$. Frank Moshé Cotacallapa Choque, 2015.

Figura 19 - Distribuição da epidemia temperada no modelo aleatório uniforme - resultado da simulação

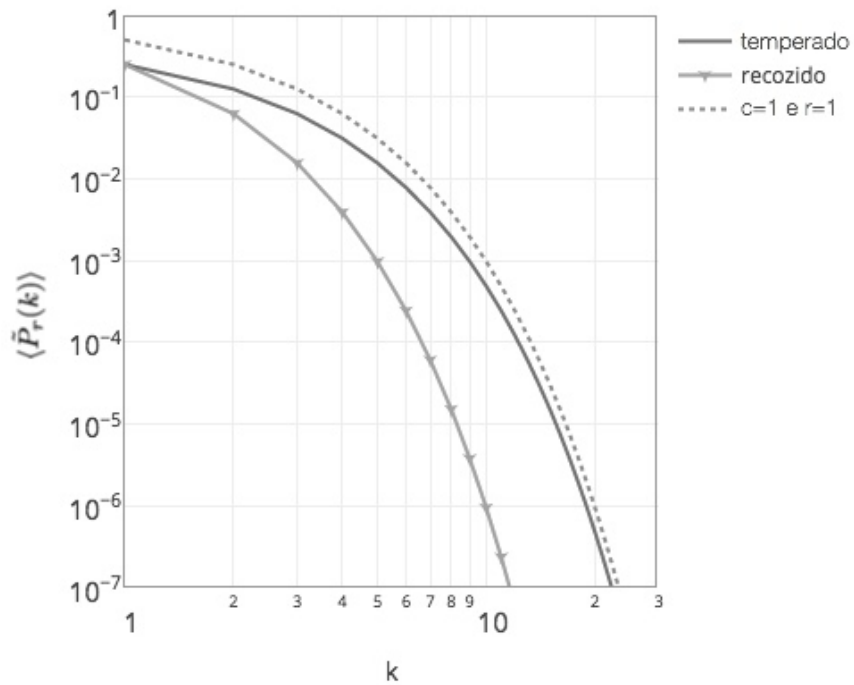

Distribuição da propagação da epidemia do modelo A baseado na rede aleatória uniforme. Frank Moshé Cotacallapa Choque, 2015 .

\subsubsection{Contágio variável sobre a rede aleatória uniforme}

Considerando a equação mestra da rede aleatória e inserindo a variável $r_{t}$, obtemos

$$
p_{r_{t}}(n, k, t+1)=r_{t}\left[\frac{1}{t}\right] p_{r_{t}}(n, k-1, t)+\left[1-\frac{1}{t}\right] p_{r_{t}}(n, k, t) .
$$


Resolvendo a equação mestra, e obtendo o valor médio da distribuição da propagação, finalmente obtemos

$$
\left\langle\tilde{P}_{r_{t}}(k)\right\rangle=c 2^{-k}
$$

para o caso temperado; notar que o resultado da equação (4.12) é o mesmo obtido do contágio fixo com variação temperada. O processo analtíco neste modelo possui maior dificuldade no cálculo comparado com o contágio fixo. Uma análise sobre essa situação será discutida mais adiante, e para maiores detalhes, ver os procedimentos no apêndice G.

\subsubsection{Contágio variável sobre a rede de Barabási-Albert}

Usando um procedimento similar ao usado na seção anterior, inserimos a decisão de contágio na equação mestra, sendo que essa decisão é variável ao longo do tempo. Desse modo, obtemos

$$
p_{r_{t}}(n, k, t+1)=r_{t}\left[\frac{k-1}{2 t}\right] p_{r_{t}}(n, k-1, t)+\left[1-\frac{k}{2 t}\right] p_{r_{t}}(n, k, t),
$$

para finalmente obter a distribuição de propagação da epidemia no caso temperado,

$$
\left\langle\tilde{P}_{r_{t}}(k)\right\rangle=\frac{4 c}{k(k+1)(k+2)} .
$$

É necessário notar que o resultado obtido (ver Figura 20) é o mesmo do contágio fixo da versão temperada sobre a rede Barabási-Albert. Isso é importante, pois mostra que mesmo tendo comportamentos diferentes, o desempenho na propagação é igual; para maior detalhe nos procedimentos usados, ver o apêndice $G$.

\subsubsection{Discussão}

É interessante notar que o resultado obtido com a decisão de contágio variável $r_{t}$ sobre o modelo de rede aleatória uniforme (seção 4.3.1) e Barabási-Albert (seção 4.3.2), é o mesmo da abordagem de contágio fixo $r$ temperado sobre as duas estruturas de rede (ver as Seções 4.2.5 e 4.2.2).

A pergunta que emerge é, como duas abordagens com diferentes regras no processo de contágio podem ter resultados iguais? No contágio temperado fixo, a decisão de contágio é fixada para cada rede construída, e a média é tomada ao fim sob todas as redes. Embora o $\left\langle\tilde{P}_{r}(k)\right\rangle$ seja o mesmo nas duas abordagens, isso não acontece com suas estruturas de rede da epidemia e, portanto, fazendo uma análise de correlação e outras medidas, tais como o número de componentes, coeficiente de aglomeração, entre outros, é possível que possuam valores diferentes. 
Adicionalmente, é necessário destacar que, em termos analíticos, a abordagem do contágio variável precisa de muitos mais recursos matemáticos para obter $\left\langle\tilde{P}_{r}(k)\right\rangle$, e isso se deve principalmente ao fato de necessitar de uma distribuição de probabilidade para cada variável $r_{t}$.

Figura 20 - Distribuição de propagação variável sobre o modelo aleatório uniforme resultado analítico

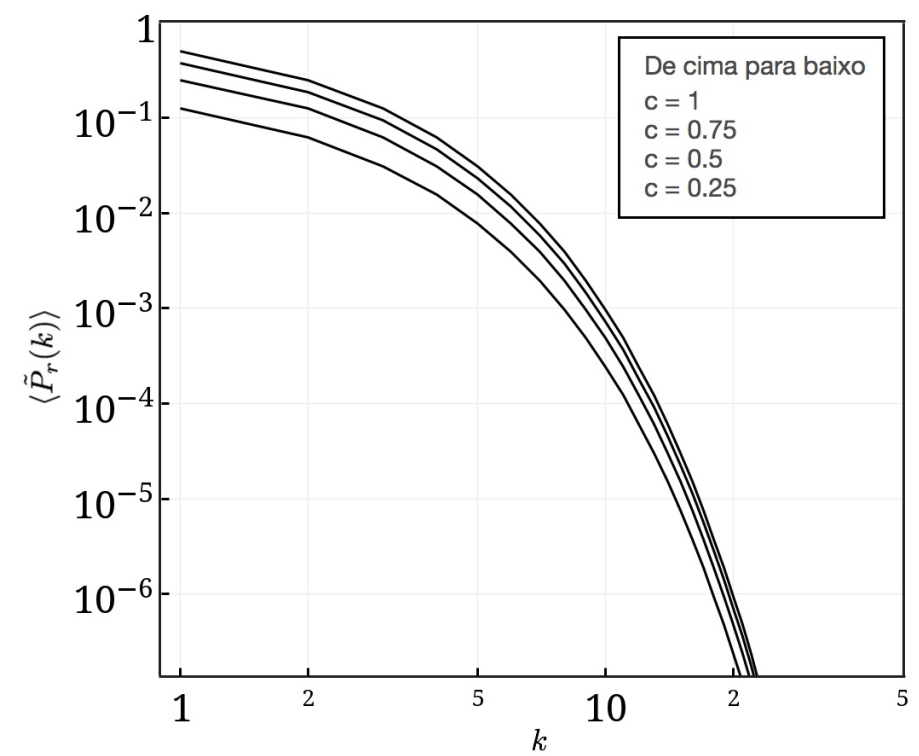

Distribuição da propagação variável baseado na rede aleatória uniforme para diferentes valores de $c$. Frank Moshé Cotacallapa

Choque, 2015.

Adicionalmente, outra variação possível que aparece no modelo de Barabási-Albert é o uso da preferência de ligação considerando apenas as ligações contagiadas. Desse modo, como visto na Figura 9, a decisão de contágio dá maior probabilidade aos nós com maior quantidade de ligações contagiadas, deixando de considerar a quantidade total de ligações (com e sem contágio). Este segundo caso pode ser ilustrado em termos de redes sociais: numa rede de amigos onde existe compartilhamento de informação, cada pessoa nova que ingressa na rede fará amizade com maior preferência com as pessoas que compartilham informação, e não necessariamente com as mais populares. Portanto, este último grupo terá vantagem sobre os outros, mesmo que estes últimos tenham muitas amizades. Esta última variação será analisada na próxima abordagem.

\subsection{Modelo C ou preferência epidêmica}

Nesta abordagem, foi escolhido a preferência epidêmica (ver a Figura 9). Assim, quando o novo nó ingressa na rede, ele terá preferência sobre os nós com maior quantidade de ligações que contagiam, sem considerar as ligações sem contágio. 
Devido ao fato de ser um modelo com maior complexidade em termos analíticos, optou-se por uma abordagem computacional, na qual se constrói uma rede com 100000 nós, e usou-se dois valores para $c=\{0.5$ e 1 $\}$. A seguinte imagem na Figura 21 mostra a média da distribuição da propagação das simulações em uma rede de Barabási-Albert.

Figura 21 - Distribuição da epidemia temperada no modelo Barabási-Albert (modelo C) resultado da simulação

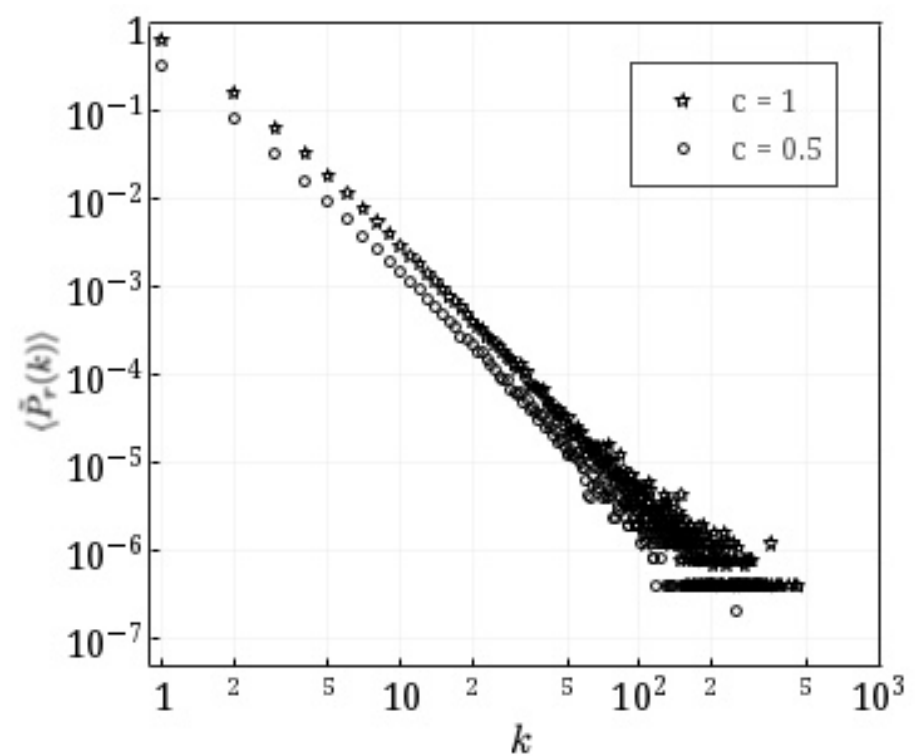

Distribuição da propagação do modelo $\mathrm{C}$ baseado na rede Barabási-Albert e com preferência epidêmica. Comparação do comportamento da rede com diferentes valores de $c=\{1,0.5\}$.

Frank Moshé Cotacallapa Choque, 2015.

\subsubsection{Discussão}

Existem duas formas de preferência de ligação adotadas no modelo de BarabásiAlbert, conforme mostrado na Figura 9. Embora seja apresentado apenas resultados por meio de simulações, é interessante notar que as duas abordagens (preferência geral e epidêmica) possuem desempenhos similares para propagar. Isso significa que mesmo dando prioridade de ligação aos nós com maior quantidade de ligações contagiadas, o desempenho é similar ao que dando preferência geral. Desse modo, o esforço de fazer a escolha de nós com mais ligações infectadas não traz nenhuma vantagem em termos de propagação.

As Figuras 21 e 22 mostram claramente a similaridade das distribuições da epidemia em termos de simulação. Cada um das simulações usou 10000 nós e 1000 repetições para cada valor de $c$. 
Figura 22 - Distribuição da epidemia na rede de Barabási-Albert com preferência geral e contágio variável

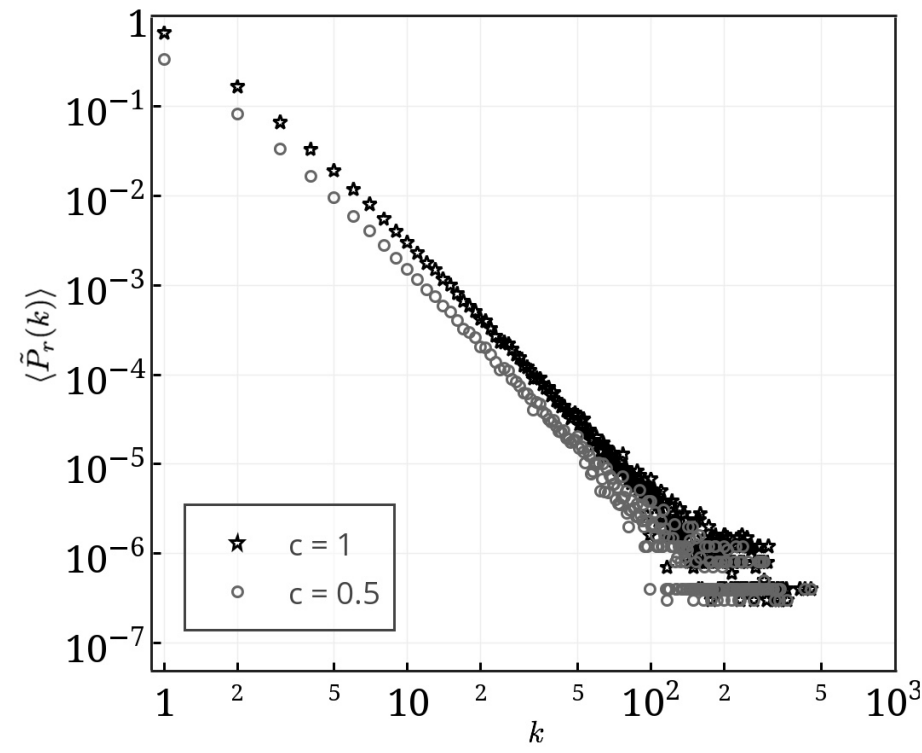

Distribuição da epidemia na rede de Barabási-Albert com contágio variável e preferência geral. Comparação do comportamento da rede com diferentes valores de $c=\{1,0.5\}$.

Frank Moshé Cotacallapa Choque, 2015. 


\section{Conclusão}

Ao longo deste texto foram expostos os fundamentos e conceitos básicos para compreender as redes complexas. Foram estudados cinco modelos de redes com diferentes abordagens, e estas foram comparadas para entender melhor o comportamento delas. Além disso, apresentou-se brevemente diferentes mecanismos de propagação de epidemias, para logo desenvolver e introduzir este fenômeno nos modelos de redes contruídos.

No primeiro modelo, que é chamado de modelo A, ou contágio fixo, foram desenvolvidas duas estruturas de redes: modelo aleatório uniforme e modelo de Barabási-Albert. Nesses modelos analíticos foram inseridas a variável $r$, que representa a decisão de contágio (sim ou não) ao longo do crescimento da rede. Além disso, foram adotadas duas formas de comportamento para a variável aleatória $r$ : temperada e recozida. Finalmente, os resultados mostraram que em qualquer uma das estruturas, a abordagem temperada possui melhor desempenho para propagar a epidemia. Outro resultado interessante é a perda da propriedade scale-free no modelo de contágio fixo recozido sobre uma rede Barabási-Albert.

No modelo B, ou contágio variável, optou-se por uma abordagem mais próxima da realidade, onde a decisão de contágio é independente para cada unidade de tempo t. Portanto, a variável de decisão de contágio é $r_{t}$. Finalmente, os resultados analíticos obtidos mostraram que a distribuição de propagação da abordagem temperada usando $r$ fixo sobre as duas estruturas de rede (aleatória uniforme e Barabási-Albert) é a mesma da abordagem onde $r_{t}$ é variável o longo do tempo. Nesse sentido, dos modelos A e B, concluiu-se que, em média, as duas formas de propagação possuem o mesmo desempenho para propagar uma epidemia, mesmo que a decisão de contágio seja temperada fixa ou variável.

De forma similar, no modelo C construiu-se a rede do modelo de Barabási-Albert, sendo que se optou pelo uso da preferência de ligação considerando apenas as ligações contagiadas sem considerar as outras ligações (sem contágio). Neste modelo preferiu-se usar os recursos computacionais, onde os resultados mostraram que a distribuição de grau reduzida teve um desempenho similar ao da abordagem B da rede de Barabási-Albert, isto é, não existe vantagem no uso da preferência epidêmica sobre a preferência geral.

\subsection{Pesquisas futuras}

Os resultados mostrados ao longo do texto tiveram como objetivo ajudar na compreensão do comportamento de uma epidemia seguindo o processo SI de contágio, lembrando que as abordagens mostradas no texto não foram desenvolvidas na literatura atual. Nesse sentido, apresenta-se algumas linhas de pesquisa futuras visando aproveitar 
os modelos desenvolvidos.

A abordagem por equações mestras, como mostrado até aqui, é uma das formas para explorar o estudo das redes complexas (não apenas a construção dos modelos de redes, mas também a construção de fenômenos dentro dela), e mostra-se como uma alternativa promissora.

No presente trabalho, optou-se como alvo obter a distribuição da propagação da epidemia dos modelos construídos, obtendo importantes resultados. Porém, na literatura de redes complexas existem muitas outras medidas importantes que podem ser analisadas nesses modelos. Portanto, visa-se uma futura pesquisa considerando medidas como coeficiente de aglomeração, componentes, resiliência, entre outros mais. 


\section{Referências}

ALBERT, R.; BARABÁSI, A.-L. Statistical mechanics of complex networks. Review of Modern Physics, v. 74, n. 1, p. 49-54, 2002. Citado na página 26.

ALI, N. Information and Decision-making Processes Leading to Corporate Failure: Enron and Red Flags. Tese (Doutorado), 2011. Citado na página 10.

ASH, R. B. Basic Probability Theory. Mineola, New York, USA: Dover Publications, Inc, 2008. 333 p. ISBN 0-486-46628-0. Citado na página 13.

BALL, F.; MOLLISON, D.; SCALIA-TOMBA, G. Epidemics with Two Levels of Mixing. The Annals of Applied Probability, Institute of Mathematical Statistics, v. 7, n. 1, p. 46-89, fev. 1997. ISSN 10505164. Disponível em: <http://www.jstor.org/stable/2245132>. Citado na página 28.

BARABÁSI, A.-L. Linked: The New Science of Networks. 1. ed. [S.l.]: Perseus Books Group; 1st edition, 2002. 256 p. Citado na página 37.

BARABÁSI, A.-L. Network Science. Northeastern University, 2013. Disponível em: $<$ http://barabasilab.neu.edu/networksciencebook/>. Citado 4 vezes nas páginas 10, 20, 26 e 27.

BARABÁSI, A.-L.; ALBERT, R. Emergence of Scaling in Random Networks. Science, v. 286, p. 509-512, 1999. Citado na página 26.

BARABÁSI, A.-L.; ALBERT, R.; JEONG, H. Mean-field theory for scale-free random networks. Physica A, v. 272, p. 173-187, 1999. Citado 2 vezes nas páginas 30 e 59.

BARABÁSI, A.-L. et al. Scale-free and hierarchical structures in complexnetworks. In: . [S.l.: s.n.], 2002. Citado 2 vezes nas páginas 26 e 59.

BOCALETTI, S. et al. Complex networks: Structure and dynamics. Physics Reports, v. 424, n. 4-5, p. 175-308, fev. 2006. ISSN 03701573. Citado na página 10.

BOLLT, E. M.; BEN-AVRAHAM, D. What is special about diffusion on scalefree nets? New Journal of Physics, v. 7, n. 1, p. 26, 2005. Disponível em: $<$ http://stacks.iop.org/1367-2630/7/i=1/a=026>. Citado na página 37.

CAMERON, P. J. Notes on Probability. London: [s.n.], 2000. 86 p. Citado na página 13.

CHAPANOND, A.; KRISHNAMOORTHY, M.; YENER, B. Graph Theoretic and Spectral Analysis of Enron Email Data. Computational \& Mathematical Organization Theory, Kluwer Academic Publishers, v. 11, n. 3, p. 265-281, 2005. ISSN 1381-298X. Citado 2 vezes nas páginas 10 e 11.

COHEN, R. et al. Resilience of the Internet to Random Breakdowns. Physical Review Letters, American Physical Society, v. 85, n. 21, p. 4626-4628, nov. 2000. Disponível em: $<$ http://link.aps.org/doi/10.1103/PhysRevLett.85.4626>. Citado na página 30.

CURRAL, S. C.; EPSTEIN, M. J. The Fragility of Organizational Trust:. Organizational Dynamics, v. 32, n. 2, p. 193-206, maio 2003. ISSN 00902616. Citado na página 10. 
DIESNER, J.; FRANTZ, T. L.; CARLEY, K. M. Communication Networks from the Enron Email Corpus "It's Always About the People. Enron is no Different". Computational 85 Mathematical Organization Theory, Kluwer Academic Publishers, v. 11, n. 3, p. 201-228, 2005. ISSN 1381-298X. Citado na página 10.

DOROGOVTSEV, S. N.; MENDES, J. F. F. Evolution of networks: From biological nets to the Internet and $W W W$. [S.l.]: Oxford University Press, USA, 2003. Citado na página 23.

ERDÖS, P.; RÉNYI, A. On the evolution of random graphs. Mathematical Institute of the Hungarian Academy of Sciences, v. 5, p. 17-61, 1960. Citado na página 25.

GRINSTEAD, C. M.; SNELL, J. L. Introduction to Probability. Second edi. Hanover, New Hampshire, USA: Dartmouth College, 1997. 510 p. Citado na página 13.

KEELING, M. J. The effects of local spatial structure on epidemiological invasions. Proceedings of the Royal Society B: Biological Sciences, v. 266, n. 1421, p. 859-867, abr. 1999. ISSN 0962-8452. Disponível em: < http://www.ncbi.nlm.nih.gov/pmc/articles/ PMC1689913/>. Citado na página 29.

MENDENHALL, W.; BEAVER, R.; BEAVER, B. Probability and Probability Distributions. In: Introduction to Probability and Statistics. 14. ed. Boston: Brooks/Cole, 2013. p. 123-174. ISBN 978-1-133-10375-2. Citado na página 15.

MÉZARD, M.; PARISI, G.; VIRASORO, M. A. Spin Glass Theory and Beyond \ M. Mezard, G. Parisi, M.A. Virasoro (eds.). World Scientific, 1987. (World Scientific lecture notes in physics). Disponível em: <https://books.google.com.br/books?id= Gpc5nwEACAAJ>. Citado na página 32.

MILGRAM, S. The Small-World Problem. Psychology Today, v. 1, n. 1, p. 61-67, 1967. Citado na página 21.

MITCHELL, M. Complex systems: Network thinking. Artificial Intelligence, v. 170, n. 18, p. 1194-1212, dez. 2006. ISSN 00043702. Citado na página 21.

NEWMAN, M.; BARABÁSI, A.-L.; WATTS, D. J. The structure and dynamics of networks. [S.l.]: Princeton University Press, 2006. 415-423 p. Citado 2 vezes nas páginas 10 e 28.

NEWMAN, M. E. J. The Structure and Function of Complex Networks. [S.1.]: Society for Industrial and Applied Mathematics, 2003. 167-256 p. Citado 2 vezes nas páginas 10 e 28.

NEWMAN, M. E. J. Networks An Introduction. [S.l.]: Oxford University Press, 2010. 720 p. Citado 5 vezes nas páginas 21, 22, 23, 27 e 28.

PASTOR-SATORRAS, R.; VESPIGNANI, A. Epidemic Spreading in Scale-Free Networks. Physical Review Letters, American Physical Society, v. 86, n. 14, p. 3200-3203, abr. 2001. Disponível em: <http://link.aps.org/doi/10.1103/PhysRevLett.86.3200>. Citado na página 29.

ROLLA, L. T. Introdução à Probabilidade. Rio de Janeiro: [s.n.], 2013. 177 p. Citado 2 vezes nas páginas 14 e 15. 
STAUFFER, D.; SAHIMI, M. Diffusion in scale-free networks with annealed disorder. Phys. Rev. E, American Physical Society, v. 72, n. 4, p. 46128, 2005. Disponível em: <http://link.aps.org/doi/10.1103/PhysRevE.72.046128>. Citado na página 37.

STEEN, M. van. Graph Theory and Complex Networks. Amsterdam, Netherlands: [s.n.], 2010. 285 p. ISBN 978-90-815406-1-2. Citado na página 20.

WATTS, D. J. A simple model of global cascades on random networks. Proceedings of the National Academy of Sciences, National Acad Sciences, v. 99, n. 9, p. 5766, 2002. Disponível em: <http://research.microsoft.com/apps/pubs/default.aspx?id=164520>. Citado na página 30.

WATTS, D. J.; STROGATZ, S. H. Collective dynamics of 'small-world' networks. Nature, v. 393, n. 6684, p. 440-442, jun. 1998. ISSN 0028-0836. Disponível em: $<$ http://dx.doi.org/10.1038/30918>. Citado na página 21. 

Apêndices 



\section{APÊNDICE A - Equação mestra para rede aleatória simples}

Seguindo o processo de construção de uma rede, usamos a equação mestra para obter a distribuição de grau $P(k)$ da rede toda,

$$
P(k, t)=\frac{1}{t} \sum_{n=1}^{t} p(n, k, t) .
$$

Como visto na seção 3.2 , a probabilidade $p(n, k, t)$ obedece à equação

$$
p(n, k, t+1)=\Pi(k-1, t) p(n, k-1, t)+(1-\Pi(k, t)) p(n, k, t),
$$

e a probabilidade do último nó $p(n, k, t=n)$ pode ter somente uma ligação,

$$
\left.p(n, k, t)\right|_{t=n}=\delta_{k, 1},
$$

onde $\delta_{i, j}=1$ quando $i=j$ e 0 quando $i \neq j$. Como mencionado no texto, adotou-se a estrutura inicial no tempo $t=2$ como sendo composta por dois nós com duas ligações entre eles. Considerou-se esta condição apenas para que a quantidade de nós na rede seja proporcional ao tempo, e assim, facilitar os seguintes cálculos matemáticos.

De (A.1) e (A.2), obtemos que

$$
\sum_{n=1}^{t} p(n, k, t+1)=t\{P(k-1, t) \Pi(k-1, t)+P(k, t)[1-\Pi(k, t)]\},
$$

onde o lado esquerdo pode ser escrito do seguinte modo:

$$
\sum_{n=1}^{t} p(n, k, t+1)=\sum_{n=1}^{t+1} p(n, k, t+1)-p(t+1, k, t+1) .
$$

Substituindo a último termo por $\delta_{k, 1}$, de acordo com (A.3), e usando (A.1), obtemos

$$
\sum_{n=1}^{t} p(n, k, t+1)=(t+1) P(k, t+1)-\delta_{k, 1} .
$$

Das equações (A.6) e (A.4), temos que

$$
(t+1) P(k, t+1)-\delta_{k, 1}=t\{P(k-1, t) \Pi(k-1, t)+P(k, t)[1-\Pi(k, t)]\} .
$$


Assim, na equação (A.7), é preciso conhecer $\Pi(k, t)$ para desenvolvê-lo. Para isso, considerando o modo mais simples e particular, onde o nó destino é ligado com um dos outros já existentes de forma equiprovável,

$$
\Pi(k, t)=\frac{1}{t}
$$

e substituindo (A.8) em (A.7), temos

$$
\begin{aligned}
& (t+1) P(k, t+1)-\delta_{k, 1}=P(k-1, t)+t P(k, t)-P(k, t) \\
& (t+1) P(k, t+1)-t P(k, t)=P(k-1, t)+\delta_{k, 1}-P(k, t)
\end{aligned}
$$

Considerando que $f^{\prime}(x)=\lim _{\Delta x \rightarrow 0} \frac{f(x+\Delta x)-f(x)}{\Delta x}$, e fazendo uma analogia desta com a primeira parte do (A.9), para $t \gg 1$, temos

$$
\frac{\partial[t P(k, t)]}{\partial t}=P(k, t)+t \frac{\partial P(k, t)}{\partial t}
$$

De (A.9) e (A.10),

$$
P(k, t)+t \frac{\partial P(k, t)}{\partial t}=P(k-1, t)+\delta_{k, 1}-P(k, t) .
$$

Depois de um longo tempo, quando $t \rightarrow \infty$, por definição $P(k, t) \rightarrow P(k)$ e assumindo o segundo termo nulo neste regime (considerando que $\frac{\partial P(k, t)}{\partial t}$ decresce mais rapidamente que o crescimento de $t)$, obtemos $P(k)=\frac{1}{2}\left(P(k-1)+\delta_{k, 1}\right)$.

De forma iterativa, $P(0)=0, P(1)=\frac{1}{2}, P(2)=\frac{1}{2^{2}}$, então $P(k)=2^{-k}$.

O grau médio é dado por

$$
\langle k\rangle=\sum_{k=1} k P(k)=\sum_{k=1} \frac{k}{2^{k}}=\sum_{k=1} k e^{k(-\ln 2)},
$$

e usando a propriedade $\sum_{k=1} k e^{-A k}=\frac{e^{A}}{\left(e^{A}-1\right)^{2}}$ onde $A>0$, obtemos que

$$
\bar{k}=\frac{e^{\ln 2}}{\left(e^{\ln 2}-1\right)^{2}}=\frac{2}{2-1}=2
$$

como esperado, considerando que a cada tempo é adicionado uma ligação e dois nós. 



\section{APÊNDICE B - Modelo de Erdős-Rényi}

Na construção do modelo de Erdős-Rényi (ER), considera-se uma quantidade $\langle m\rangle$ ligações, onde ela é igual à probabilidade $p$ de fazer a ligacão vezes a quantidade máxima possível $\left(\begin{array}{l}n \\ 2\end{array}\right)$ de ligações,

$$
\langle m\rangle=\left(\begin{array}{l}
n \\
2
\end{array}\right) p
$$

Começando com este resultado e o grau médio $\langle k\rangle=\frac{2\langle m\rangle}{n}$ de um nó, obtemos

$$
\langle k\rangle=\frac{2\left(\begin{array}{c}
n \\
2
\end{array}\right) p}{n}=(n-1) p ;
$$

portanto, a quantidade média de ligações que tem um nó neste modelo de rede é igual à probabilidade $p$ vezes a quantidade dos outros nós $n-1$. Se escolhermos um valor constante $c=(n-1) p$ para este resultado, onde $n$ representa um valor grande, deve-se ter $p$ suficientemente pequeno para garantir o valor constante de $c$. A probabilidade de um nó ter $k$ ligações seria $p^{k}(1-p)^{n-1-k}$, e fazendo a extensão deste resultado para a rede toda obtemos a probabilidade binomial

$$
P(k)=\left(\begin{array}{c}
n-1 \\
k
\end{array}\right) p^{k}(1-p)^{n-1-k} .
$$

Analisando o caso em que a quantidade de nós é grande, isto é, quando $n \rightarrow+\infty$, e a quantidade de ligações para cada nó é constante, obtemos da equação (B.3)

$$
P(k)=\alpha\left(1-\frac{c}{n-1}\right)^{n-1-k}
$$

onde

$$
\alpha=\frac{(n-1) !}{k !(n-1-k) !} \frac{c^{k}}{(n-1)^{k}} \simeq \frac{c^{k}}{k !}
$$

onde se usou $\frac{(n-1) !}{(n-1-k) !} \simeq(n-1)^{k}$ e por definição $\lim _{x \rightarrow \pm \infty}(1+1 / x)^{x}=e$, que implicou

$$
\left(1-\frac{c}{n-1}\right)^{n-1-k} \simeq e^{-c}
$$

Das equações (B.4), (B.5) e (B.6),

$$
P(k)=\frac{c^{k} e^{-c}}{k !} .
$$





\section{APÊNDICE C - Modelo de Barabási-Albert}

O modelo de Barabási-Albert é conhecido basicamente pelo fato de ter uma estrutura de rede mais próxima das redes reais em relação a ER, sendo assim uma das redes complexas mais analisadas. Neste apêndice procura-se mostrar a construção da distribuição de probabilidade dos graus da rede mediante a abordagem das equações diferenciais conforme mostrado nos artigos de Barabási, Albert e Jeong (1999) e Barabási et al. (2002).

Como condição inicial considera-se a rede começando com $n_{0}$ nós, e ao longo do tempo $t$, novos nós são adicionados ao grafo com probabilidade $\Pi\left(k_{i}\right)$ proporcional ao grau do nó que recebe a ligação,

$$
\Pi\left(k_{i}\right)=\frac{k_{i}}{\sum_{j} k_{j}} .
$$

Assume-se que cada novo nó tem a possibilidade de fazer $m_{0}$ ligações, sendo que $m_{0} \leq n_{0}$. Depois de um tempo $t$, com $n_{t}$ nós e $m_{t}$ ligações na rede, tem-se

$$
n_{t}=n_{0}+t
$$

e

$$
m_{t}=\frac{\sum_{j=1}^{n} k_{i}}{2}=m_{0} t
$$

\section{Abordagem por equações diferenciais}

Se os nós são adicionados de modo constante (a cada paso de tempo), onde $k_{i}$ é uma variável real contínua, de (C.3) temos a seguinte equação diferencial:

$$
\frac{\partial k_{i}}{\partial t}=m_{0} \Pi\left(k_{i}\right)=\frac{k_{i}}{2 t}
$$

Resolvendo a equação e lembrando que cada nó é adicionado a cada passo de tempo, temos

$$
\int_{m_{0}}^{k_{i}(t)} \frac{d k_{i}}{k_{i}}=\int_{t_{i}}^{t} \frac{d t}{2 t}
$$


e obtemos

$$
k_{i}(t)=m_{0}\left(\frac{t}{t_{i}}\right)^{1 / 2}
$$

Isto mostra que o grau do nó cresce com a raíz quadrada do tempo. Por outro lado, sabemos que

$$
P(k)=\frac{\mathrm{d}\left(P\left(k_{i}(t)<k\right)\right)}{\mathrm{d} k} .
$$

Usando a equação (C.6),

$$
\begin{aligned}
P\left(k_{i}(t)<k\right) & =P\left(m_{0}\left(\frac{t}{t_{i}}\right)^{1 / 2}<k\right) \\
& =P\left(m_{0}^{2} \frac{t}{t_{i}}<k^{2}\right) \\
& =P\left(t_{i}>\frac{m_{0}^{2} t}{k^{2}}\right),
\end{aligned}
$$

donde se tem

$$
P\left(k_{i}(t)<k\right)=1-P\left(t_{i} \leq \frac{m_{0}^{2} t}{k^{2}}\right)=1-\frac{m_{0}^{2} t}{\left(n_{0}+t\right) k^{2}},
$$

onde foi assumido que os vértices entram em intervalos regulares de tempo. Usando a equação (C.7) e (C.9), temos

$$
P(k)=\frac{\partial P\left(k_{i}<k\right)}{\partial k}=\frac{2 m_{0}^{2} t}{\left(n_{0}+t\right) k^{3}}
$$

Tomando $t \rightarrow \infty$,

$$
P(k) \sim \frac{2 m_{0}^{2}}{k^{3}}
$$

Esta equação mostra que a distribuição de grau segue uma lei de potência, assim, para grau $k$ suficientemente grande, a equação é reduzida à $P(k) \sim k^{-3}$.

\section{Abordagem por equação mestra}

Outra abordagem para construir o modelo de Barabási-Albert é usar a equação mestra. Assim, de (A.2) e usando a probabilidade de ligação

$$
\Pi(k, t)=\frac{k}{2 t},
$$


onde $k$ representa o grau do nó, e assumiu-se a condição inicial como no Apêndice A. Desta forma, podemos dizer que $2 t$ é a quantidade total de ligações que tem a rede no instante $t$.

Fazendo o procedimento análogo de (A.8) até (A.11), obtemos

$$
P(k)-\delta_{k, 1}=\frac{(k-1) P(k-1)-k P(k)}{2},
$$

que leva a

$$
P(k)=\frac{k-1}{k+2} P(k-1)+\frac{2}{k+2} \delta_{k, 1} .
$$

Resolvendo iterativamente, e considerando a função $\delta_{k, 1}$ apenas quando $k=1$,

$$
\begin{aligned}
& k=1, P(1)=\frac{2}{3}, \\
& k=2, P(2)=\frac{1}{4} P(1)=\frac{2}{3 \cdot 4}, \\
& k=3, P(3)=\frac{2}{5} P(2)=\frac{4}{3 \cdot 4 \cdot 5}, \\
& k=4, P(4)=\frac{3}{6} P(3)=\frac{4}{4 \cdot 5 \cdot 6},
\end{aligned}
$$

e, portanto,

$$
P(k)=\frac{4}{k(k+1)(k+2)} .
$$





\section{APÊNDICE D - Código de geração de redes em Python}

Código usando o pacote NetworkX da linguagem de programação Python.

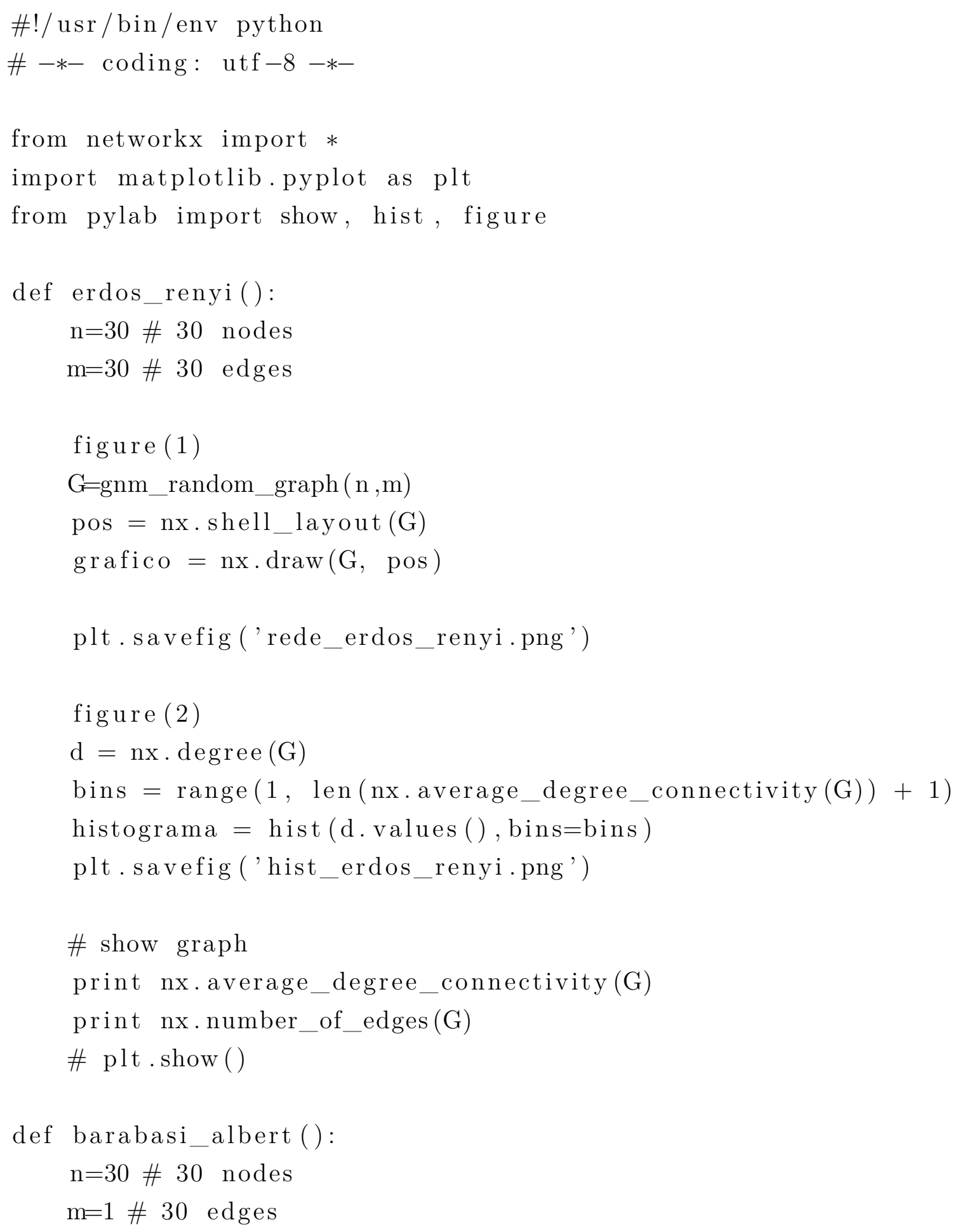




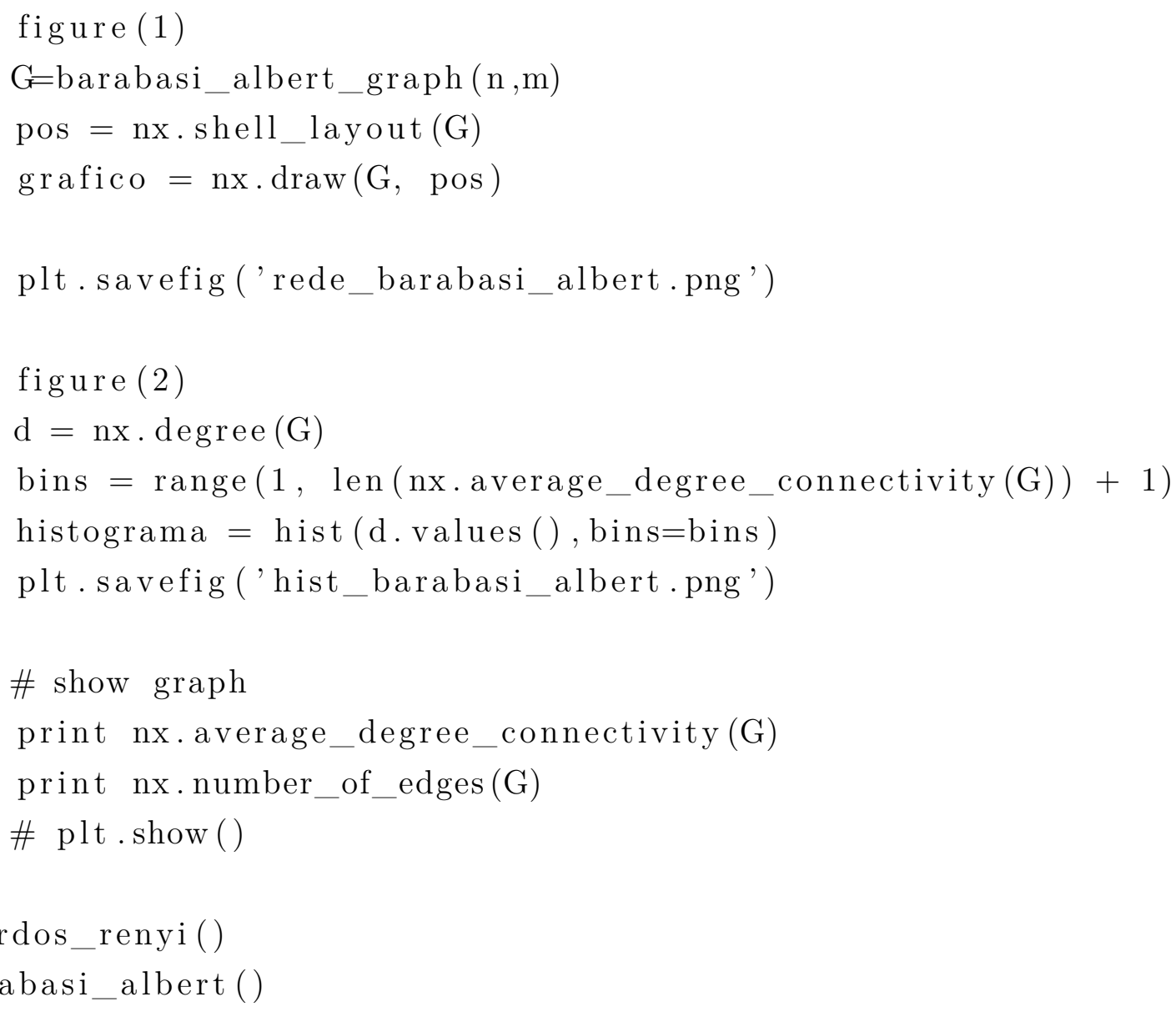





\section{APÊNDICE E - Transformada Z - Modelo de Barabási-Albert}

A transformada Z é uma ferramenta para resolver equações de diferenças finitas, e é definida como

$$
X(z)=\sum_{n=0}^{\infty} x(n) z^{n}
$$

Usando a definição da transformada $\mathrm{Z}$ na distribuição $P(k)$, obtemos

$$
X(z)=\sum_{k \geq 0} P(k) z^{k}
$$

Expandindo a somatória e aplicando derivada nas equações, e tomando $z=0$, temos:

$$
\begin{aligned}
X(z) & =P(0)+P(1) z+P(2) z^{2}+P(3) z^{3}+P(4) z^{4}+\ldots+P(n) z^{n}+\ldots \\
X(0) & =P(0) \\
X^{\prime}(z) & =P(1)+2 P(2) z+3 P(3) z^{2}+4 P(4) z^{3}+\ldots+n P(n) z^{n-1}+\ldots \\
X^{\prime}(0) & =P(1) \rightarrow P(1)=\frac{1}{1 !} X^{\prime}(z=0) \\
X^{\prime \prime}(z) & =2 P(2) z+3 \cdot 2 \cdot P(3) z+4 \cdot 3 \cdot P(4) z^{2}+\ldots+n(n-1) P(n) z^{n-2}+\ldots \\
X^{\prime \prime}(0) & =2 P(2) \rightarrow P(2)=\frac{1}{2 !} X^{\prime \prime}(z=0)
\end{aligned}
$$

Tendo em consideração que o valor procurado é $P(k)$, de (E.3), e sabendo que $k \geqslant 0$ e $k \in \mathbb{Z}$, chega-se à transformação inversa

$$
P(k)=\frac{1}{k !} \lim _{z \rightarrow 0} \frac{d^{k} X(z)}{d z^{k}} .
$$

Assim, usando a transformada Z na equação mestra de (C.13),

$$
P(k)-\delta_{k, 1}=\frac{(k-1) P(k-1)-k P(k)}{2},
$$


temos

$$
\sum_{k \geq 0} P(k) z^{k}=\sum_{k \geq 0} \frac{(k-1) P(k-1) z^{k}}{2}-\sum_{k \geq 0} \frac{k P(k) z^{k}}{2}+\sum_{k \geq 0} \delta_{k, 1} z^{k},
$$

e da definição (E.2), temos

$$
X(z)=\sum_{k \geq-1} \frac{k P(k) z^{k+1}}{2}-\sum_{k \geq 0} \frac{k P(k) z^{k}}{2}+z,
$$

e usando $P(-1)=P(0)=0$, temos

$$
\begin{aligned}
& X(z)=\frac{z}{2} \sum_{k \geq 1} k P(k) z^{k}-\frac{1}{2} \sum_{k \geq 1} k P(k) z^{k}+z \\
& X(z)=\frac{z-1}{2} \sum_{k \geq 1} k P(k) z^{k}+z .
\end{aligned}
$$

Se tomarmos a derivada de $X(z)$ em (E.2), encontramos

$$
z X^{\prime}(z)=\sum_{k \geq 1} k P(k) z^{k}
$$

e usando este resultado e substituindo em (E.8), obtemos

$$
\begin{aligned}
X(z) & =\frac{z-1}{2} z X^{\prime}(z)+z \\
0 & =X^{\prime}(z)-\frac{2 X(z)}{z(z-1)}+\frac{2 z}{z(z-1)} .
\end{aligned}
$$

Para resolver esta equação, usamos a seguinte identidade: dada a equação

$$
\begin{aligned}
& 0=G^{\prime}(x)+A(x) \cdot G(x)+B(x), \text { então } \\
& G(x)=G\left(y_{0}\right) e^{\int_{y}^{y_{0}} A(\bar{y}) d \bar{y}}-\int_{y_{0}}^{y} B(\breve{y}) e^{\int_{y}^{\breve{y}} A(\bar{y}) d \bar{y}} d \breve{y}
\end{aligned}
$$

De (E.10) e (E.11), obtemos

$$
X(z)=\frac{-2(z-1)^{2} \ln (1-z)+3 z^{2}-2 z}{z^{2}} .
$$

Usando $\ln (1-z)=-\sum_{p \geq 1} \frac{z^{p}}{p}$, temos

$$
X(z)=\frac{4 \sum_{p \geq 1} z^{p}}{p(p+1)(p+2)}
$$


lembrando que $0 \leq z<1$.

Usando este resultado em (E.4), temos

$$
P(k)=\frac{4}{k(k+1)(k+2)} .
$$





\section{APÊNDICE F - Propagação de epidemia}

\section{Modelo A}

Considerando a propagação da epidemia onde a decisão de contágio é representado por $r$, e inserindo essa variável na equação mestra do modelo de Barabási-Albert, tem-se

$$
p_{r}(n, k, t+1)=r\left[\frac{k-1}{2 t}\right] p_{r}(n, k-1, t)+\left[1-\frac{k}{2 t}\right] p_{r}(n, k, t),
$$

onde $r$ representa a propagação entre dois nós e a sua distribuição é

$$
\mathcal{P}(r)=c \delta_{r, 1}+(1-c) \delta_{r, 0}, \quad c \in[0,1] \subset \mathbb{R}
$$

Além disso,

$$
\langle r\rangle=\sum_{r=0,1} r \mathcal{P}(r)=c
$$

Usando a equação (A.7), e fazendo o procedimento de (A.8) até (A.11), obtemos

$$
\tilde{P}_{r}(k)=\frac{(k-1) \tilde{P}_{r}(k-1) r+2 \delta_{k, 1}}{k+2}
$$

onde $\tilde{P}_{r}(k)$ representa a distribuição da rede da epidemia, que é uma subrede da rede de Barabási-Albert. Além disso, é preciso lembrar que a função $\tilde{P}_{r}(k)$ não é normalizada.

Ante esta equação, temos duas situações.

\section{Processo recozido ou annealed na rede de Barabási-Albert}

Neste caso, $r \rightarrow\langle r\rangle$, ou seja,

$$
\tilde{P_{\langle r\rangle}}(k)=\frac{(k-1) \tilde{P_{\langle r\rangle}}(k-1)\langle r\rangle+2 \delta_{k, 1}}{k+2} .
$$

Resolvendo iterativamente e usando (F.3),

$$
\tilde{P_{\langle r\rangle}}(k)=\frac{4 c^{k-1}}{k(k+1)(k+2)} .
$$


Para $k \gg 1$, obtemos

$$
\tilde{P_{\langle r\rangle}}(k)=\frac{4 c^{k-1}}{k^{3}}
$$

\section{Processo temperado ou quenched em rede Barabási-Albert}

A segunda opção é obter a média de $\tilde{P}_{r}(k)$. Assim, de (F.4),

$$
\tilde{P}_{r}(k)=\frac{4 r^{k-1}}{k(k+1)(k+2)} .
$$

Tomando-se a média da função acima via

$$
\left\langle\tilde{P}_{r}(k)\right\rangle=\sum \tilde{P}_{r}(k) \mathcal{P}(r)
$$

tem-se

$$
\left\langle\tilde{P}_{r}(k)\right\rangle=\sum_{r=1,0} \frac{4 r^{k-1}}{k(k+1)(k+2)}\left[(1-c) \delta_{r, 0}+(c) \delta_{r, 1}\right]
$$

que leva a

$$
\left\langle\tilde{P}_{r}(k)\right\rangle=\frac{4 c}{k(k+1)(k+2)}
$$

Para $k \gg 1$, obtemos

$$
\left\langle\tilde{P}_{r}(k)\right\rangle=\frac{4 c}{k^{3}}
$$

\section{Rede aleatória uniforme}

Do mesmo modo que as duas últimas abordagens desenvolvidas para o modelo A, foram construídos os modelos temperado e recozido para redes aleatórias uniforme.

Inserimos a variável aleatória $r$ na equação mestra do modelo de rede aleatória uniforme, considerando que $r$ representa a decisão de contágio da epidemia. Desse modo,

$$
p_{r}(n, k, t+1)=r\left[\frac{1}{t}\right] p_{r}(n, k-1, t)+\left[1-\frac{1}{t}\right] p_{r}(n, k, t)
$$

logo, usando a equação (A.7), e fazendo o procedimento de (A.8) até (A.11), obtemos

$$
\tilde{P}_{r}(k)=\frac{\tilde{P}_{r}(k-1) r+\delta_{k, 1}}{2}
$$


Nesta última equação, $\tilde{P}_{r}(k)$ representa a distribuição da rede da epidemia. Novamente, a função $\tilde{P}_{r}(k)$ não é normalizada.

De (F.14), temos duas abordagens para obter a distribuição de grau da rede de contágio da epidemia.

\section{Processo recozido ou annealed em rede aleatória uniforme}

Neste caso, $r \rightarrow\langle r\rangle$, ou seja,

$$
\tilde{P_{\langle r\rangle}}(k)=\frac{\tilde{P_{\langle r\rangle}}(k-1)\langle r\rangle+\delta_{k, 1}}{2} .
$$

Resolvendo iterativamente e usando (F.3),

$$
\tilde{P_{\langle r\rangle}}(k)=\frac{c^{k-1}}{2^{k}}
$$

\section{Processo temperado ou quenched em rede aleatória uniforme}

A segunda abordagem consiste em obter a média de diferentes redes construídas. Resolvendo iterativamente a equação (F.14), temos

$$
\tilde{P}_{r}(k)=\frac{r^{k-1}}{2^{k}} .
$$

Tomando-se a média com respeito à distribuição (F.2), tem se

$$
\left\langle\tilde{P}_{r}(k)\right\rangle=\sum_{r=1,0} \frac{r^{k-1}}{2^{k}}\left[(1-c) \delta_{r, 0}+(c) \delta_{r, 1}\right]
$$

que leva a

$$
\left\langle\tilde{P}_{r}(k)\right\rangle=c 2^{-k}
$$





\section{APÊNDICE G - Contágio variável}

\section{Contágio variável sobre a rede aleatória uniforme}

Para obter $\left\langle p_{r}(n, k, t)\right\rangle$, consideramos a equação mestra da rede aleatória onde é inserido o valor da decisão $r_{t} \in\{0,1\}$ da propagação da epidemia, que é independente para cada nó que ingressa na rede,

$$
p_{r}(n, k, t+1)=\left[\frac{r_{t}}{t}\right] p_{r}(n, k-1, t)+\left[1-\frac{1}{t}\right] p_{r}(n, k, t) .
$$

Além disso, é definido o valor da probabilidade $\mathcal{P}\left(r_{t}\right)$ da decisão de propagar

$$
\mathcal{P}\left(r_{t}\right)=c \delta\left(r_{t}-1\right)+(1-c) \delta\left(r_{t}\right), \quad c \in[0,1] \subset \mathbb{R}
$$

O conjunto $\left\{r_{t}\right\}$ é formado por variáveis aleatórias independentes e identicamente distribuídas. Assim, multiplicando (G.1) por $\mathcal{P}\left(r_{t}\right)$ e $r_{t}$, e observando que $\left(r_{t}\right)^{2}=r_{t}$, temos

$$
r_{t} \mathcal{P}\left(r_{t}\right) p_{r}(n, k, t+1)=\frac{r_{t}}{t} \mathcal{P}\left(r_{t}\right) p_{r}(n, k-1, t)+\left[1-\frac{1}{t}\right] r_{t} \mathcal{P}\left(r_{t}\right) p_{r}(n, k, t)
$$

Definindo $q_{r_{t}}:=r_{t} \mathcal{P}\left(r_{t}\right) p_{r_{t}}(n, k, t)$, temos

$$
q_{r_{t}}(n, k, t+1)=\left[\frac{1}{t}\right] q_{r_{t}}(n, k-1, t)+\left[1-\frac{1}{t}\right] q_{r_{t}}(n, k, t) .
$$

Considere a identidade $p_{r_{t}}=\left(1-r_{t}\right) p_{r_{t}}+r_{t} p_{r_{t}}$; multiplicando-a por $\mathcal{P}\left(r_{t}\right)$ e integrando-a em $[0,1]$,

$$
\int_{0}^{1} \mathrm{~d} r_{t} \mathcal{P}\left(r_{t}\right) p_{r_{t}}=\int_{0}^{1} \mathrm{~d} r_{t}\left(1-r_{t}\right) \mathcal{P}\left(r_{t}\right) p_{r_{t}}+\int_{0}^{1} \mathrm{~d} r_{t} r_{t} \mathcal{P}\left(r_{t}\right) p_{r_{t}}
$$

O objetivo é determinar

$$
\left\langle p_{r}(n, k, t)\right\rangle=\int_{0}^{1} \mathrm{~d} r_{t} \mathcal{P}\left(r_{t}\right) p_{r_{t}}
$$

Por outro lado, considere

$$
\psi(R)=\int_{0}^{R} \mathrm{~d} r_{t}\left(R-r_{t}\right) \mathcal{P}\left(r_{t}\right) p_{r_{t}}+\chi(R),
$$


onde

$$
\psi(R)=\int_{0}^{R} \mathrm{~d} r_{t} \mathcal{P}\left(r_{t}\right) p_{r_{t}} \quad \text { e } \quad \chi(R)=\int_{0}^{R} \mathrm{~d} r_{t} r_{t} \mathcal{P}\left(r_{t}\right) p_{r_{t}}
$$

que recupera a equação (G.5) para $R=1$. Em particular $\left\langle p_{r}(n, k, t)\right\rangle=\psi(R=1)$, que é nosso principal objetivo. Para isso, aplicamos a transformada de Laplace em ambos lados da equação (G.7), com

$$
\psi^{L}(\zeta):=\int_{0}^{\infty} \mathrm{d} R e^{-\zeta R} \psi(R), \quad \chi^{L}(\zeta):=\int_{0}^{\infty} \mathrm{d} R e^{-\zeta R} \chi(R)
$$

Então,

$$
\psi^{L}(\zeta)=\int_{0}^{\infty} \mathrm{d} R e^{-\zeta R} \int_{0}^{R} \mathrm{~d} r_{t} \mathcal{P}\left(r_{t}\right) p_{r_{t}}, \quad \chi^{L}(\zeta)=\int_{0}^{\infty} \mathrm{d} R e^{-\zeta R} \int_{0}^{R} \mathrm{~d} r_{t} r_{t} \mathcal{P}\left(r_{t}\right) p_{r_{t}}
$$

e obtemos

$$
\psi^{L}(\zeta)=\alpha+\chi^{L}(\zeta)
$$

onde

$$
\alpha:=\int_{0}^{\infty} e^{-\zeta R} \mathrm{~d} R \int_{0}^{R}\left(R-r_{t}\right) \mathcal{P}\left(r_{t}\right) p_{r_{t}} \mathrm{~d} r_{t}
$$

Mudando a ordem das integrais,

$$
\alpha=\int_{0}^{\infty} \mathcal{P}\left(r_{t}\right) p_{r_{t}} \mathrm{~d} r_{t} \int_{r_{t}}^{\infty} e^{-\zeta R}\left(R-r_{t}\right) \mathrm{d} R,
$$

e da segunda integral, usando o método de integração por substituição com $u=R-r_{t}$,

$$
\int_{r_{t}}^{\infty} e^{-\zeta R}\left(R-r_{t}\right) \mathrm{d} R=\frac{e^{-\zeta r_{t}}}{\zeta^{2}}
$$

então,

$$
\alpha=\frac{1}{\zeta^{2}} \int_{0}^{\infty} \mathcal{P}\left(r_{t}\right) p_{r_{t}} e^{-\zeta r_{t}} \mathrm{~d} r_{t}
$$

Por outro lado, no primeiro membro de (G.11), temos

$$
\psi^{L}(\zeta)=\int_{0}^{\infty} \mathcal{P}\left(r_{t}\right) p_{r_{t}} \mathrm{~d} r_{t} \int_{r_{t}}^{\infty} e^{-\zeta R} \mathrm{~d} R,
$$


que é

$$
\psi^{L}(\zeta)=\frac{1}{\zeta} \int_{0}^{\infty} \mathcal{P}\left(r_{t}\right) p_{r_{t}} e^{-\zeta r_{t}} \mathrm{~d} r_{t}
$$

Da última equação e (G.15) em (G.11), finalmente temos

$$
\psi^{L}(\zeta)=\frac{\psi^{L}(\zeta)}{\zeta}+\chi^{L}(\zeta)
$$

$\mathrm{Ou}$

$$
\psi^{L}(\zeta)=\frac{\zeta \chi^{L}(\zeta)}{\zeta-1}
$$

Por outro lado, contínuando da equação (G.4) e aplicando a transformada $Z$,

$$
\sum_{k=1}^{\infty} z^{k} q_{r_{t}}(n, k, t+1)=\sum_{k=1}^{\infty} z^{k} \frac{q_{r_{t}}(n, k-1, t)}{t}+\sum_{k=1}^{\infty} z^{k}\left(1-\frac{1}{t}\right) q_{r_{t}}(n, k, t) .
$$

De

$$
\sum_{k=1}^{\infty} z^{k} \frac{q_{r_{t}}(n, k-1, t)}{t}=\sum_{k=0}^{\infty} z^{k+1} \frac{q_{r_{t}}(n, k, t)}{t}
$$

usando $q_{r_{t}}(n, k=0, t)=0$ e fatorando termos iguais, obtemos

$$
\sum_{k=1}^{\infty} z^{k} q_{r_{t}}(n, k, t+1)=\left(1-\frac{1}{t}+\frac{z}{t}\right) \sum_{k=1}^{\infty} z^{k} q_{r_{t}}(n, k, t)
$$

Assim, substituindo iterativamente para $t, t-1, t-2, \ldots$, até o momento que o nó foi adicionado na rede $t=n$, finalmente obtemos que

$$
\sum_{k=1}^{\infty} z^{k} q_{r_{t}}(n, k, t)=\left[\prod_{\ell=n}^{t-1} \frac{\ell-1+z}{\ell}\right]\left[\sum_{k=1}^{\infty} z^{k} q_{r_{t}}(n, k, t=n)\right]
$$

e da transformação inversa (E.4), temos

$$
q_{r_{t}}(n, k, t)=\frac{1}{k !} \frac{\mathrm{d}^{k}}{\mathrm{~d} z^{k}}\left[\prod_{\ell=n}^{t-1} \frac{\ell-1+z}{\ell} r_{t} \mathcal{P}\left(r_{t}\right) \sum_{k=1}^{\infty} z^{k} p_{r_{t}}(n, k, t=n)\right]_{z \downarrow 0} .
$$

A probabilidade $p_{r_{t}}(n, k, t=n)$ só não é nula quando $k=1$, considerando que o nó $n$ é o último que entrou na rede e não pode ter $k>2$ ligações; então,

$$
q_{r_{t}}(n, k, t)=r_{t} \mathcal{P}\left(r_{t}\right) \frac{1}{k !} \frac{\mathrm{d}^{k}}{\mathrm{~d} z^{k}}\left[z \prod_{\ell=n}^{t-1} \frac{\ell-1+z}{\ell}\right]_{z \downarrow 0} .
$$


Como sabemos que $\chi(R)=\int_{0}^{R} \mathrm{~d} r_{t} q_{r_{t}}(n, k, t)$, então

$$
\chi(R)=\int_{0}^{R} \mathrm{~d} r_{t} r_{t} \mathcal{P}\left(r_{t}\right) \frac{1}{k !} \frac{\mathrm{d}^{k}}{\mathrm{~d} z^{k}}\left[z \prod_{\ell=n}^{t-1} \frac{\ell-1+z}{\ell}\right]_{z \downarrow 0}
$$

e integrando as variáveis que estão em função de $r_{t}$ considerando a distribuição (G.2),

$$
\chi(R)=\frac{1}{k !} \frac{\mathrm{d}^{k}}{\mathrm{~d} z^{k}}\left[z \prod_{\ell=n}^{t-1} \frac{\ell-1+z}{\ell}\right]_{z \downarrow 0} \beta
$$

onde

$$
\beta=\int_{0}^{R} r_{t}\left[c \delta\left(r_{t}-1\right)+(1-c) \delta\left(r_{t}\right)\right] \mathrm{d} r_{t}
$$

$\mathrm{ou}$

$$
\beta=c \theta(R-1),
$$

onde

$$
\theta(x)= \begin{cases}1, & x \geq 0 \\ 0, & x<0\end{cases}
$$

Assim, substituindo estes resultados em (G.27), vemos que

$$
\chi(R)=c a(n, k, t) \theta(R-1),
$$

onde

$$
a(n, k, t)=\frac{1}{k !} \frac{\mathrm{d}^{k}}{\mathrm{~d} z^{k}}\left[z \prod_{l=n}^{t-1} \frac{l-1+z}{l}\right]_{z \downarrow 0} \operatorname{com} \prod_{l=n}^{n-1}(\cdots)=1,
$$

e obtemos a transformada de Laplace

$$
\chi^{L}(\zeta)=\int_{0}^{\infty} e^{-\zeta R} \chi(R) \mathrm{d} R=\int_{0}^{\infty} c a(n, k, t) \theta(R-1) e^{-\zeta R} \mathrm{~d} R .
$$

Da equação (G.19) sabemos que para obter o valor de $\psi^{L}(\zeta)$ precisamos de $\chi^{L}(\zeta)$; portanto, obtendo a transformada de Laplace

$$
\chi^{L}(\zeta)=c a(n, k, t) \int_{0}^{\infty} \theta(R-1) e^{-\zeta R} \mathrm{~d} R=\frac{c a(n, k, t) e^{-\zeta}}{\zeta}
$$


e, usando (G.19), temos

$$
\psi^{L}(\zeta)=\frac{c a(n, k, t) e^{-\zeta}}{\zeta-1}
$$

Como nosso alvo é obter $\left\langle p_{r}(n, k, t)\right\rangle=\psi(R=1)$, então procuramos a transformada inversa de Laplace de $\psi^{L}(\zeta)$, que é

$$
\psi(R)=c a(n, k, t) e^{R-1} \theta(R-1)
$$

Isto pode ser verificado com a transformada de Laplace de (G.36),

$$
\begin{aligned}
\psi^{L}(\zeta) & =\int_{0}^{\infty} \mathrm{d} R e^{-\zeta R} c a(n, k, t) e^{R-1} \theta(R-1) \\
& =\frac{c a(n, k, t)}{e} \int_{0}^{\infty} \mathrm{d} R e^{-\zeta R+R} \theta(R-1) \\
& =\frac{c a(n, k, t) e^{-\zeta}}{\zeta-1}
\end{aligned}
$$

Para obter o valor de $\psi(R=1)$, substituimos $R=1$ em (G.36), e temos

$$
\left\langle p_{r}(n, k, t)\right\rangle=\psi(R=1)=c a(n, k, t)
$$

Indo além deste resultado, com o objetivo de obter $\left\langle\tilde{P}_{r}(k)\right\rangle$ partindo de $\left\langle p_{r}(n, k, t)\right\rangle$, desenvolvemos o valor de $a(n, k, t)$ da equação (G.32) fatorando algumas variáveis do produto,

$$
a(n, k, t)=\frac{1}{k !} \frac{\mathrm{d}^{k}}{\mathrm{~d} z^{k}}\left[z\left(\frac{z-1+n}{n}\right)\left(\frac{z-1+n+1}{n+1}\right) \cdots\left(\frac{z-1+t-1}{t-1}\right)\right]_{z \downarrow 0}
$$

$\mathrm{ou}$

$$
a(n, k, t)=\frac{1}{k !} \frac{(n-1) !}{(t-1) !} \frac{\mathrm{d}^{k}}{\mathrm{~d} z^{k}}[z(z+n-1)(z+n)(z+n+1) \cdots(z+t-2)]_{z \downarrow 0} .
$$

Desenvolvendo,

$$
a(n, k, t)=\frac{1}{k !} \frac{(n-1) !}{(t-1) !} k \frac{\mathrm{d}^{k-1}}{\mathrm{~d} z^{k-1}}\left[\prod_{l=n}^{t-1}(z+l-1)\right]_{z \downarrow 0},
$$

e, desse modo, fazendo a derivada iterativamente, e substituindo $\prod_{l=n}^{t-1}(z+l-1)=\omega$, então 


$$
\begin{aligned}
\frac{\mathrm{d} \omega}{\mathrm{d} z} & =\frac{\omega}{z+n-1}+\frac{\omega}{z+n}+\cdots+\frac{\omega}{z+t-2}, \\
\frac{\mathrm{d}^{2} \omega}{\mathrm{d} z^{2}} & =\frac{\omega}{(z+n-1)(z+n)}+\frac{\omega}{(z+n-1)(z+n+1)}+\cdots \\
& +\frac{\omega}{(z+n-1)(z+t-2)}+\cdots+\frac{\omega}{(z+t-2)(z+t-1)},
\end{aligned}
$$

e chegamos ao padrão onde se $k-1>t-n$, então o valor de $\omega$ é zero. Juntando com o caso $0 \leq k-1 \leq t-n$, o resultado é

$$
\frac{\mathrm{d}^{k-1}}{\mathrm{~d} z^{k-1}}\left[\prod_{l=n}^{t-1}(z+l-1)\right]_{z \downarrow 0}=\left\{\begin{array}{cc}
\frac{(t-2) !}{(n-2) !} \sum_{n \leq i_{1}, \ldots, i_{k-1} \leq t-1} \frac{1}{\left(i_{1}-1\right) \cdots\left(i_{k-1}-1\right)}, & 0 \leq k-1 \leq t-n \\
0, & t-1>t-n
\end{array}\right.
$$

onde $i_{r} \neq i_{s}$ se $r \neq s$ e, portanto,

$$
a(n, k, t)=\frac{(n-1)}{(t-1)} \frac{1}{(k-1) !} \sum_{n \leq i_{1}, \ldots, i_{k-1} \leq t-1} \frac{1}{\left(i_{1}-1\right) \cdots\left(i_{k-1}-1\right)} .
$$

Nesta última equação, os índices da somatória são todos diferentes. Contudo, podemos aproximála por uma soma onde são incluídos termos onde há índices com o mesmo valor. O erro cometido torna-se desprezível para valores suficientemente grandes de $n$ e $t$.

Portanto, para $1 \ll n, t$,

$$
a(n, k, t) \sim \frac{n}{t} \frac{1}{(k-1) !}\left(\sum_{i=n}^{t} \frac{1}{i}\right)^{k-1}
$$

e transformando a somatória em integral,

$$
\langle p(n, k, t)\rangle \sim \frac{c}{(k-1) !} \frac{n}{t}\left(\int_{n}^{t} \frac{\mathrm{d} x}{x}\right)^{k-1}=\frac{c}{(k-1) !} \frac{n}{t} \ln ^{k-1}\left(\frac{t}{n}\right) .
$$

Usando o último resultado,

$$
\left\langle\tilde{P}_{r}(k, t)\right\rangle=\frac{1}{t} \int_{0}^{t}\langle p(n, k, t)\rangle \mathrm{d} n \sim \frac{1}{t} \int_{0}^{t} \frac{c}{(k-1) !} \frac{n}{t} \ln ^{k-1}\left(\frac{t}{n}\right) \mathrm{d} n
$$

e substituindo $\frac{n}{t}=u(\mathrm{~d} n=t \mathrm{~d} u)$, obtemos

$$
\left\langle\tilde{P}_{r}(k)\right\rangle=\lim _{t \rightarrow+\infty}\left\langle\tilde{P}_{r}(k, t)\right\rangle=\frac{c(-1)^{k-1}}{(k-1) !} \int_{0}^{1} \mathrm{~d} u u \ln ^{k-1} u
$$


Com a mudança de variável $y=\ln u$, temos

$$
\left\langle\tilde{P}_{r}(k)\right\rangle=\frac{c(-1)^{k-1}}{(k-1) !} \int_{-\infty}^{0} e^{2 y} y^{k-1} \mathrm{~d} y .
$$

Usando integração por partes, nota-se que

$$
\int_{-\infty}^{0} e^{2 y} y^{k-1} \mathrm{~d} y=(-1)^{1} \int_{-\infty}^{0}(k-1) y^{k-2} \frac{e^{2 y}}{2^{1}} \mathrm{~d} y=(-1)^{2} \int_{-\infty}^{0}(k-1)(k-2) y^{k-3} \frac{e^{2 y}}{2^{2}} \mathrm{~d} y
$$

e, iterativamente,

$$
\int_{-\infty}^{0} e^{2 y} y^{k-1} \mathrm{~d} y=\frac{(-1)^{k-1}(k-1) !}{2^{k}}
$$

Dessa forma, de (G.48) e (G.50),

$$
\left\langle\tilde{P}_{r}(k)\right\rangle=c 2^{-k}
$$

\section{Contágio variável sobre a rede de Barabási-Albert}

No contágio variável sobre a rede Barabási-Albert, a abordagem é a mesmo a da rede aleatória uniforme. É considerada uma variável $r_{t} \in\{0,1\}$ que representa a decisão de contágio variável a cada unidade de tempo e que é inserida na equação mestra da rede Barabási-Albert.

Portanto, a equação mestra do contágio é

$$
p_{r_{t}}(n, k, t+1)=\left[\frac{r_{t}(k-1)}{2 t}\right] p_{r_{t}}(n, k-1, t)+\left[1-\frac{k}{2 t}\right] p_{r_{t}}(n, k, t) .
$$

Multiplicando por $r_{t}$ nos dois lados da equação, obtemos

$$
r_{t} p_{r_{t}}(n, k, t+1)=\left[\frac{r_{t}(k-1)}{2 t}\right] p_{r_{t}}(n, k-1, t)+r_{t}\left[1-\frac{k}{2 t}\right] p_{r_{t}}(n, k, t),
$$

sendo que $\left(r_{t}\right)^{2}=r_{t}$.

Substituindo $q_{r_{t}}(n, k, t):=r_{t} p_{r_{t}}(n, k, t)$, temos que

$$
q_{r_{t}}(n, k, t+1)=\left[\frac{k-1}{2 t}\right] q_{r_{t}}(n, k-1, t)+\left[1-\frac{k}{2 t}\right] q_{r_{t}}(n, k, t),
$$


e, aplicando a transformada $Z$, temos

$$
\sum_{k=1}^{\infty} z^{k} q_{r_{t}}(n, k, t+1)=\sum_{k=1}^{\infty} z^{k} \frac{(k-1)}{2 t} q_{r_{t}}(n, k-1, t)+\sum_{k=1}^{\infty} z^{k}\left(1-\frac{k}{2 t}\right) q_{r_{t}}(n, k, t),
$$

onde a transformada $Z$ de $q_{r_{t}}$ é

$$
Z(n, z, t)=\sum_{k=1}^{\infty} z^{k} q_{r_{t}}(n, k, t)
$$

Como

$$
\begin{gathered}
\frac{\partial}{\partial z} Z(n, z, t)=z \frac{\partial}{\partial z}\left[\sum_{k=1}^{\infty} z^{k} q_{r_{t}}(n, k, t)\right] \\
\frac{\partial}{\partial z} Z(n, z, t)=\sum_{k=1}^{\infty} k z^{k-1} q_{r_{t}}(n, k, t) \\
\frac{\partial}{\partial z} Z(n, z, t)=\sum_{k=1}^{\infty}(k-1) z^{k-2} q_{r_{t}}(n, k-1, t)
\end{gathered}
$$

e substituindo os valores de (G.56), (G.57) e (G.58) na equação (G.55), tem-se

$$
Z(n, z, t+1)=z^{2}\left[\frac{1}{2 t}\right] \frac{\partial}{\partial z} Z(n, z, t)+Z(n, z, t)-z\left[\frac{1}{2 t}\right] \frac{\partial}{\partial z} Z(z, n, t),
$$

e arrajando a equação, chega-se a

$$
Z(n, z, t+1)-Z(n, z, t)=z(z-1)\left[\frac{1}{2 t}\right] \frac{\partial}{\partial z} Z(n, z, t)
$$

Para tempos longos, pode-se escrever o primeiro membro desta equação como

$$
Z(n, z, t+1)-Z(n, z, t)=\frac{\partial}{\partial t} Z(n, z, t)
$$

e então obtemos

$$
\frac{\partial}{\partial t} Z(n, z, t)-\frac{z(z-1)}{2 t} \frac{\partial}{\partial z} Z(n, z, t)=0
$$

Usando o método das características, e fazendo $z=z(t)$,construímos a equação

$$
\frac{\partial}{\partial t} Z(n, z(t), t)+\frac{\mathrm{d} z}{\mathrm{~d} t} \frac{\partial}{\partial z} Z(n, z, t)=\frac{\mathrm{d}}{\mathrm{d} t} Z(n, z(t), t)
$$


Desse modo, de (G.62) e (G.63), obtemos duas equações,

$$
\begin{aligned}
\frac{\mathrm{d}}{\mathrm{d} t} Z(n, z(t), t) & =0 \\
\frac{\mathrm{d} z}{\mathrm{~d} t} & =\frac{-z(z-1)}{2 t}
\end{aligned}
$$

Da primeira equação, considerando que a derivada é 0 , o valor de $Z(n, z(t), t)$ é constante ao longo da curva característica $z=z(t)$

$$
Z(n, z(t), t)=Z(n, z(n), t=n)=\text { cte. }
$$

Aliás, quando $t=n$, ou seja, quando a última ligação é adicionada na rede, temos

$$
q_{r_{t}}(n, k, t=n):=r_{t} p_{r_{t}}(n, k, t=n)=r_{t=n} \delta_{k, 1}
$$

e usando isso na transformada Z

$$
Z(n, z, t=n)=\sum_{k=1}^{\infty} z^{k} r_{t=n} \delta_{k, 1}=r_{t=n} z_{t=n}
$$

Portanto,

$$
Z(n, z(t=n), t=n)=r_{t=n} z_{t=n}=r_{n} z_{n}
$$

Resolvendo a equação (G.64), temos

$$
\begin{aligned}
\int_{n}^{t} \frac{\mathrm{d} t}{2 t} & =\int_{z_{n}}^{z} \mathrm{~d} z\left[\frac{1}{z}-\frac{1}{z-1}\right] \\
\frac{1}{2} \ln \left|\frac{t}{n}\right| & =\ln \left|\frac{z}{z-1} \frac{z_{n}-1}{z_{n}}\right| \\
{\left[\frac{t}{n}\right]^{1 / 2} } & =\frac{z}{z-1} \frac{z_{n}-1}{z_{n}},
\end{aligned}
$$

e finalmente,

$$
z_{n}=\frac{1}{1+\frac{1-z}{z}\left[\frac{t}{n}\right]^{1 / 2}} .
$$

Das equações (G.68), (G.72) e (G.65),

$$
Z(n, z, t)=r_{n} \frac{z}{\alpha+(1-\alpha) z},
$$


onde $\alpha=\left[\frac{t}{n}\right]^{1 / 2}$.

De (E.4), sabemos que

$$
q_{r_{t}}(n, k, t)=\frac{1}{k !} \frac{\mathrm{d}^{k}}{\mathrm{~d} z^{k}}[Z(n, z, t)]_{z \downarrow 0},
$$

e, usando a equação (G.73), temos

$$
\begin{aligned}
q_{r_{t}}(n, k, t) & =\frac{r_{n}}{k !} \frac{\mathrm{d}^{k}}{\mathrm{~d} z^{k}}\left[\frac{z}{\alpha+(1-\alpha) z}\right]_{z \downarrow 0} \\
& =\frac{r_{n} k}{k !} \frac{\mathrm{d}^{k-1}}{\mathrm{~d} z^{k-1}}\left[(\alpha+(1-\alpha) z)^{-1}\right]_{z \downarrow 0},
\end{aligned}
$$

Substituindo

$$
\gamma z=(\alpha+(1-\alpha) z)^{-1}
$$

na $(k-1)$-ésima derivada de $\gamma z$ e tomando $z \downarrow 0$ leva a

$$
\left[\frac{\mathrm{d}^{k-1}}{\mathrm{~d} z^{k-1}} \gamma z\right]_{z \downarrow 0}=r_{n}(\alpha-1)^{k-1} \alpha^{-k}(k-1) !
$$

e lembrando que $\alpha=\left[\frac{t}{n}\right]^{1 / 2}$, obtemos da equação (G.75) que

$$
\begin{aligned}
q_{r_{n}}(n, k, t) & =r_{n} \frac{(\alpha-1)^{k-1}}{\alpha^{k}} \\
& =r_{n} \frac{1}{\left[\frac{t}{n}\right]^{1 / 2}-1}\left[1-\left(\frac{n}{t}\right)^{1 / 2}\right]^{k}
\end{aligned}
$$

Da equação (G.38) sabemos que

$$
p_{r}(n, k, t)=\psi(R=1)
$$

portanto, da relação que existe entre $\chi$ e $\psi$ (G.20), primeiro, é necessário obter (G.8)

$$
\begin{aligned}
\chi(R) & =\int_{0}^{R} \mathcal{P}\left(r_{t}\right) q_{r_{t}}(n, k, t) \mathrm{d} r_{t} \\
& =\int_{0}^{R} \mathcal{P}\left(r_{t}\right) r_{n} \frac{1}{\left[\frac{t}{n}\right]^{1 / 2}-1}\left[1-\left(\frac{n}{t}\right)^{1 / 2}\right]^{k} \\
& =r_{n} \frac{1}{\left[\frac{t}{n}\right]^{1 / 2}-1}\left[1-\left(\frac{n}{t}\right)^{1 / 2}\right]^{k} \theta(R-1) .
\end{aligned}
$$


Fazendo

$$
b_{r}(n, k, t):=r_{n} \frac{1}{\left[\frac{t}{n}\right]^{1 / 2}-1}\left[1-\left(\frac{n}{t}\right)^{1 / 2}\right]^{k}
$$

obtemos $\chi(R)=b_{r}(n, k, t) \theta(R-1)$; desse modo, usando a transformada de Laplace, temos

$$
\begin{aligned}
\chi^{L}(\zeta) & =\int_{0}^{\infty} e^{-\zeta R} \chi(R) \mathrm{d} R \\
& =\int_{0}^{\infty} e^{-\zeta R} \chi(R) b_{r}(n, k, t) \theta(R-1) \mathrm{d} R \\
& =b_{r}(n, k, t) \frac{e^{-\zeta}}{\zeta} .
\end{aligned}
$$

De $(G .8)$

$$
\begin{aligned}
\psi^{L}(\zeta) & =\frac{\zeta \chi^{L}(\zeta)}{\zeta-1} \\
& =\frac{b_{r}(n, k, t) e^{-\zeta}}{\zeta-1}
\end{aligned}
$$

donde obtemos a transformada inversa de Laplace,

$$
\psi(R)=b_{r}(n, k, t) e^{R-1} \theta(R-1)
$$

Sabendo que $p_{r_{t}}(n, k, t)=\psi(R=1)$,

$$
p_{r_{t}}(n, k, t)=b_{r}(n, k, t)=r_{n} \frac{\left(1-\sqrt{\left(\frac{n}{t}\right)^{k}}\right.}{\sqrt{\left(\frac{t}{n}\right)}-1} .
$$

Como $p_{r_{t}}(n, k, t)$ é uma distribuição marginal, temos

$$
p_{r_{t}}(n, k, t)=\int \mathrm{d} r_{1} \ldots \mathrm{d} r_{t-1} \mathcal{P}\left(r_{1}\right) \ldots \mathcal{P}\left(r_{t-1}\right) p_{r}(n, k, t)
$$

portanto,

$$
p_{r_{t}}(n, k, t)=\int \mathrm{d} r_{n} \mathcal{P}\left(r_{n}\right) p_{r_{t}}(n, k, t),
$$


para $n \neq t$. Além disso, obtendo a média de $p_{r}(n, k, t)$, temos

$$
\left\langle p_{r}(n, k, t)\right\rangle= \begin{cases}\int \mathrm{d} r_{t} \mathcal{P}\left(r_{t}\right) p_{r_{t}}(n, k, t), & n=t \\ \int \mathrm{d} r_{t} \mathcal{P}\left(r_{t}\right) \underbrace{\int \mathrm{d} r_{n} \mathcal{P}\left(r_{n}\right) p_{r_{t}}(n, k, t)}_{=p_{r_{t}}(n, k, t)}, & n \neq t .\end{cases}
$$

Usando (G.89) e integrando em (G.92),

$$
\left\langle p_{r}(n, k, t)\right\rangle=c \frac{\left(1-\sqrt{\frac{n}{t}}\right)^{k}}{\sqrt{\frac{t}{n}}-1} .
$$

Obtendo $\left\langle\tilde{P}_{r}(k, t)\right\rangle$

$$
\left\langle\tilde{P}_{r}(k, t)\right\rangle=\frac{1}{t} \int_{0}^{t} \mathrm{~d} n c \frac{\left(1-\sqrt{\frac{n}{t}}\right)^{k}}{\sqrt{\frac{t}{n}}-1},
$$

substituindo $u=\frac{n}{t}$ e integrando,

$$
\begin{aligned}
\left\langle\tilde{P}_{r}(k, t)\right\rangle & =\int_{0}^{1} \mathrm{~d} u c \frac{1}{u^{-1 / 2}-1}\left(1-u^{1 / 2}\right)^{k} \\
& =c \int_{0}^{1} \mathrm{~d} u \frac{u^{1 / 2}}{1-u^{1 / 2}}\left(1-u^{1 / 2}\right)^{k} \\
& =c \int_{0}^{1} \mathrm{~d} u u^{1 / 2}\left(1-u^{1 / 2}\right)^{k-1}
\end{aligned}
$$

e substituindo novamente com $y=1-u^{1 / 2}$, tem-se

$$
\begin{aligned}
\left\langle\tilde{P}_{r}(k, t)\right\rangle & =c \int_{0}^{1} \mathrm{~d} y 2(1-y)^{2} y^{k-1} \\
& =2 c \int_{0}^{1} \mathrm{~d} y\left(1-2 y+y^{2}\right) y^{k-1} \\
& =2 c \int_{0}^{1} \mathrm{~d} y\left(y^{k-1}-2 y^{k}+y^{k+1}\right) \\
& =2 c\left[\frac{y^{k}}{k}-\frac{2 y^{k+1}}{k+1}+\frac{y^{k+2}}{k+2}\right]_{0}^{1} \\
& =2 c\left[\frac{1}{k}-\frac{2}{k+1}+\frac{1}{k+2}\right] \\
& =2 c\left[\frac{2}{k(k+1)(k+2)}\right]
\end{aligned}
$$

e, finalmente,

$$
\left\langle\tilde{P}_{r}(k, t)\right\rangle=\frac{4 c}{k(k+1)(k+2)} .
$$


Para $t \rightarrow \infty$, tem-se

$$
\left\langle\tilde{P}_{r}(k)\right\rangle=\frac{4 c}{k(k+1)(k+2)} .
$$

